\title{
Glycan-dependent binding of galectin-1 to neuropilin-1 promotes axonal regeneration after spinal cord injury
}

\author{
HR Quintá ${ }^{1}$, JM Pasquini ${ }^{\star, 1,4}$, GA Rabinovich ${ }^{\star 2,3,4}$ and LA Pasquini ${ }^{\star * 1,4}$
}

Following spinal cord injury (SCI), semaphorin $3 \mathrm{~A}$ (Sema3A) prevents axonal regeneration through binding to the neuropilin-1 (NRP-1)/PlexinA4 receptor complex. Here, we show that galectin-1 (Gal-1), an endogenous glycan-binding protein, selectively bound to the NRP-1/PlexinA4 receptor complex in injured neurons through a glycan-dependent mechanism, interrupts the Sema3A pathway and contributes to axonal regeneration and locomotor recovery after SCl. Although both Gal-1 and its monomeric variant contribute to de-activation of microglia, only high concentrations of wild-type Gal-1 (which co-exists in a monomer-dimer equilibrium) bind to the NRP-1/PlexinA4 receptor complex and promote axonal regeneration. Our results show that Gal-1, mainly in its dimeric form, promotes functional recovery of spinal lesions by interfering with inhibitory signals triggered by Sema3A binding to NRP-1/PlexinA4 complex, supporting the use of this lectin for the treatment of SCl patients. Cell Death and Differentiation (2014) 21, 941-955; doi:10.1038/cdd.2014.14; published online 21 February 2014

Spinal cord injury (SCI), an insult that results in a change either temporary or permanent in normal motor, sensory or autonomic function, remains a major challenge in biomedicine. ${ }^{1}$ This pathological process involves the interplay of several factors, including matricellular proteins and pro-inflammatory cytokines, which contribute to inhibit axonal regeneration post lesion. Semaphorin 3A (Sema3A), a soluble member of the semaphorin superfamily, inhibits axonal regeneration following $\mathrm{SCl}$ by acting on microtubules and actin cytoskeleton. ${ }^{2-5}$ During neuronal development, Sema3A directs axonal guidance through binding to the neuronal receptor neuropilin-1 (NRP-1), serving as an anti-attractant molecule for axonal growth. 6,7 Binding of Sema3A to NRP-1 requires the formation of a complex with PlexinA4, another member of the semaphorin family, essential for triggering intracellular signaling events. ${ }^{8,9}$ Sema3A is mainly secreted by meningeal fibroblasts in the injured area and contributes to inadequate axonal regeneration after $\mathrm{SCl}^{3,9}$ Interestingly, expression of Sema3A in adult intact spinal cord is barely detectable; however, when the lesion occurs, its levels increase considerably due to breakdown of meningeal coverings, leading to migration of Sema3A-expressing fibroblasts to the lesion site and inclusion of these cells into the glial scar. ${ }^{3}$ After $\mathrm{SCl}$, descendent motor tracts and neighboring neurons express distinct components of the Sema3A signaling pathway, mainly NRP-1 and PlexinA4, which make them sensitive to Sema3A binding and inhibition of axonal regeneration. ${ }^{4,10-12}$ Thus, interruption of Sema3A signaling may lead to axonal regeneration and functional recovery after $\mathrm{SCl}$.

Galectin-1 (Gal-1), a member of a highly conserved family of animal lectins, binds to the common disaccharide (Gal $\beta 1-4)$ GlcNAc) on both $N$ - and $O$-glycans decorating cell surface glycoconjugates. This lectin exists in a monomer-dimer equilibrium depending on its relative concentration and biochemical features of different tissues. ${ }^{13}$ Within the CNS, Gal-1 controls proliferation of adult neural progenitor cells, ${ }^{14,15}$ regulates neurogenesis and promotes functional recovery after stroke. ${ }^{16}$ Expression of Gal-1 correlates with the regenerative potential of spinal motoneurons after SCl. ${ }^{17-19}$ Recently, we found that Gal-1 prevents neurodegeneration and promotes neuroprotection in a model of autoimmune neuroinflammation by promoting microglia deactivation. ${ }^{20}$ However, in spite of considerable progress, the mechanistic basis of these findings and their therapeutic implications in a setting relevant to human $\mathrm{SCl}$ remain unexplored.

Here we evaluated the consequences of Gal-1 treatment in situ in an in vivo model of $\mathrm{SCl}$ which allowed the assessment of full locomotor recovery. We found that high concentrations of Gal-1 (>7 $\mu \mathrm{M})$, which favor a shift toward the dimeric form of this protein, promoted full locomotor

\footnotetext{
${ }^{1}$ Departamento de Química Biológica, Instituto de Química y Físico Química Biológica, Universidad de Buenos Aires, Buenos Aires C1113AAD, Argentina; ${ }^{2}$ Laboratorio de Inmunopatología, Instituto de Biología y Medicina Experimental (IBYME), Consejo Nacional de Investigaciones Científicas y Técnicas (CONICET), Buenos Aires C1428, Argentina and ${ }^{3}$ Laboratorio de Glicómica Funcional, Departamento de Química Biológica, Facultad de Ciencias Exactas y Naturales, Universidad de Buenos Aires, Buenos Aires C1428, Argentina

${ }^{*}$ Corresponding author: JM Pasquini or LA Pasquini, Departamento de Química Biológica, Instituto de Química y Físico Química Biológica, Fac. de Farmacia y Bioquímica, Universidad de Buenos Aires, Junin 956, Buenos Aires, C1113AAD, Argentina. Tel: +54 1149648287 ; Fax: +54 1149648288. E-mail: jpasquin@qb.ffyb.uba.ar or laupasq@yahoo.com

or GA Rabinovich, Vuelta de Obligado 2490- C1428 Ciudad de Buenos Aires, Buenos Aires, Argentina. Tel: +54 1147832869 (ext. 266 ); Fax: +54 11 47862564. E-mail: gabyrabi@gmail.com

${ }^{4}$ These authors contributed equally to this work and should be considered senior authors. Keywords: galectin-1; neuropilin-1; neuroregeneration; semaphorin 3A; spinal cord injury Abbreviations: BBB, Basso-Beattie-Bresnahan; CTB, cholera toxin $\beta$-subunit; GFAP, glial fibrillary acidic protein; ggals1 $^{-1-}$, galectin-1-deficient; Gal-1-N46D, galectin-1 mutant lacking carbohydrate binding activity; Gal-1, wild-type galectin-1 form occurring in a monomer-dimer equilibrium; M-Gal-1, galectin-1 stable monomeric mutant; NF-M, Neurofilament-M; NRP-1, neuropilin-1; PSF, Point Spread Function; Sema3A, semaphorin 3A; SCI, spinal cord injury; WT, wild type

Received 29.9.13; revised 17.12.13; accepted 03.1.14; Edited by RA Knight; published online 21.2.14
} 
recovery in the $\mathrm{SCl}$ model. In contrast to the effects on microglial deactivation which were observed using either Gal-1 or a monomeric mutant of this lectin lacking dimerization capacity, neuroregeneration as well as full locomotor recovery were observed only when lesions were exposed to the dimeric form of this protein. Mechanistically we show that Gal-1 bound to the NRP-1/PlexinA4 receptor complex on injured neurons through a glycan-depending mechanism. This interaction blocked binding of Sema3A to this receptor complex and promoted full axonal regeneration, leading to locomotor functional recovery. Our results highlight the therapeutic potential of stable dimeric Gal-1 as a feasible therapy for patients with $\mathrm{SCl}$.

\section{Results}

Gal-1 promotes locomotor function recovery after SCl. To investigate the mechanisms underlying the neuroregenerative effects of Gal-1, we studied the role of this glycan-binding protein in axon regeneration after $\mathrm{SCl}$ using a complete transection model. To avoid spontaneous spinal reflex self-recovery, analysis of different parameters was performed at early time periods and finalized on day 7 post $\mathrm{SCl}$. We analyzed the behavior of $\mathrm{Lgals}^{-1-}$ (galectin-1deficient) and wild-type (WT) mice subjected to $\mathrm{SCl}$ and further treated either with WT recombinant Gal-1 (co-existing in a dimer-monomer equilibrium) or with vehicle control (PBS). To assess mouse hindlimb movement, we used the 21-point open field Basso-Beattie-Bresnahan (BBB) locomotor rating scale (BBB scoring) (Figure 1a). All mice suffered hindlimb paralysis immediately after transection. Whereas hindlimb paralysis showed virtually no recovery in vehicle-treated $\mathrm{Lgals}^{-1}$ mice (BBB score: $0.35 \pm 0.3$ ), Lgals $1^{-1-}$ mice treated with 0.5 or $1 \mu \mathrm{g} / \mu \mathrm{l} \mathrm{Gal}-1$ showed a significant increase in BBB score $(12 \pm 0.5$ and $16 \pm 0.7$, respectively) $(P<0.001)$. A representative video sequence of vehicle-treated $L$ gals $1^{-1-}$ mice illustrated no significant movement in hindlimbs and no weight support. These mice were unable to keep their balance and dragged their abdomen and tail. Moreover, they showed spinal column hunching and dorsal placement of a fully extended and immobile paw, as well as a total disability to keep on top of the bridge-shaped metal grid (Figure $1 \mathrm{~b}$ and Supplementary Figure S1). In contrast, Lgals $1^{-1-}$ mice treated with $1 \mu \mathrm{g} / \mu \mathrm{l}$ Gal-1 showed a substantial recovery of hindlimb function, which helped keeping a normal position instead of falling on one side. These animals showed a locomotor behavior similar to sham animals, that is, using all four limbs and lifting their tails. They also exhibited minimal shaking and faster movements (Figure 1c and Supplementary Figure S2). Furthermore, the grid-walking apparatus test was performed to evaluate motor coordination, which depends on descending motor control and ascending flow of proprioceptive and tactile information. ${ }^{21,22}$ These animals showed a low number of foot fall errors $(3 \pm 1)$. Similar results were obtained in sham animals (Supplementary Figure S3). These results suggest that an early intervention with Gal-1 is sufficient to prevent hindlimb loss of function. Remarkably, WT mice treated with vehicle control displayed significantly higher but limited BBB score $(\sim 4 \pm 0.65)$ than vehicle-treated $L$ gals $1^{-1-}$ mice $(P<0.001$, Figure 1a), indicating that the absence of endogenous Gal-1 prevents recovery of spontaneous motor function. Vehicle-treated WT mice successfully balanced for short periods of time, although they remained leaning on one side. Their self-recovery was mainly evidenced in paw position during stance by the degree of trunk stability and the decreased frequency of dorsal stepping (data not shown). Surprisingly, when comparing treatments with Gal-1 in WT versus Lgals $^{-1}$ - mice, we found similar locomotor recovery levels using only the highest dose of Gal-1 $(1 \mu \mathrm{g} / \mu \mathrm{l})$ (BBB score: $14.5 \pm 0.9$ ), while a lower dose of this lectin $(0.5 \mu \mathrm{g} / \mu \mathrm{l})$ induced significantly less recovery in WT as a

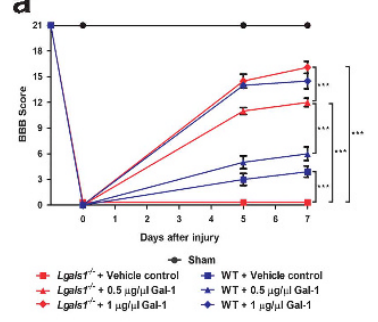

b

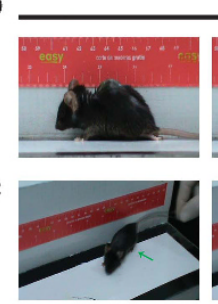

d 7 days post-injury

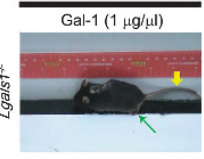

Lgals $1^{+\leftarrow,}, 7$ days post-injury
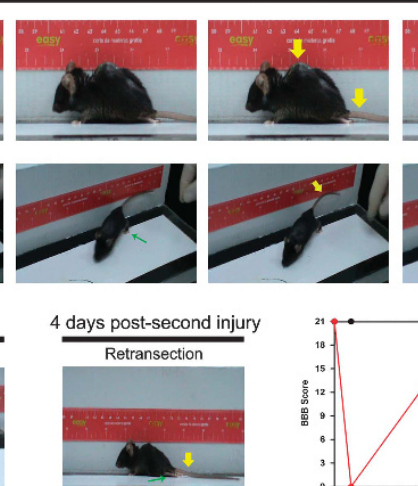
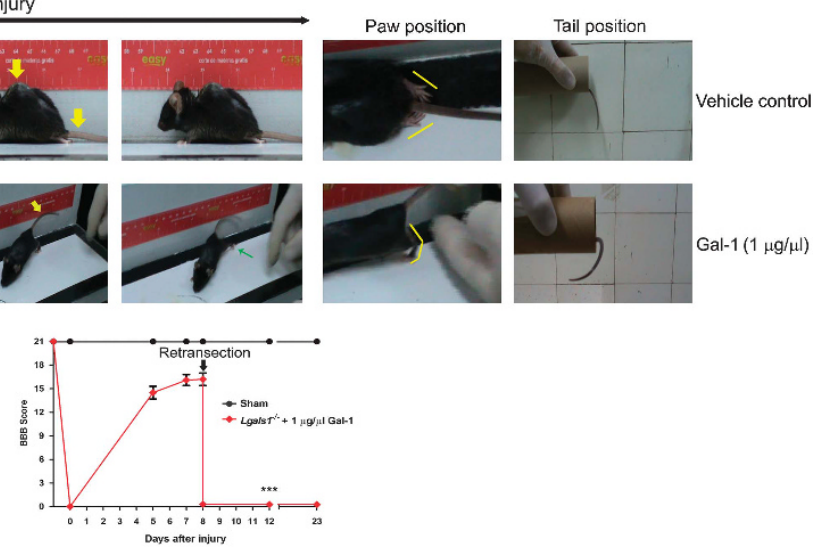

Figure 1 Evaluation of mouse hindlimb movements. (a) BBB scoring of Lgals $1^{-/-}$and WT mice treated with $0.5 \mu \mathrm{g} / \mu \mathrm{l}$ or $1 \mu \mathrm{g} / \mu \mathrm{l}$ Gal-1. Values represent the mean \pm S.D. of seven independent experiments ( $n=3$ mice per group). ${ }^{* * *} P<0.001$ using one-way ANOVA followed by Tukey's tests. (b) Representative video images of injured vehicle-treated-Lgals $1^{-/-}$mice. Yellow arrows show spinal column and tail position. The right images show placement of paw (yellow lines) and tail position. (c) Representative video images of injured Lgals $1^{-1-}$ mice treated with $1 \mu \mathrm{g} / \mu \mathrm{l} \mathrm{Gal-1.} \mathrm{Green} \mathrm{arrows} \mathrm{show} \mathrm{a} \mathrm{complete} \mathrm{cycles} \mathrm{of} \mathrm{hindlimb} \mathrm{movement.} \mathrm{The} \mathrm{yellow} \mathrm{arrow} \mathrm{in} \mathrm{the}$ same images shows tail position. The right images indicate the paw articulation placement (yellow lines) and also show tail position. (d) The left picture corresponds to a representative injured Lgals $1^{-1-}$ mice treated with $1 \mu \mathrm{g} / \mu \mathrm{l}$ Gal-1 analyzed 7 days post injury. The right picture corresponds to the same animal after retransection and shows paw and tail position (green and yellow arrows, respectively). The right bar graph shows BBB scoring after 1 and 4 days post retransection. Values represent the mean \pm S.D. of three independent experiments ( $n=5$ mice per group). ${ }^{* * \star} P<0.001$ using one-way ANOVA followed by Tukey's tests 
compared with Lgals $1^{-1-}$ mice (BBB score: $6 \pm 0.8$ versus $12 \pm 0.5$, respectively) $(P<0.001$, Figure $1 \mathrm{a})$.

To further understand the cellular basis of this neuroregenerative effect, we evaluated whether the functional recovery induced by Gal-1 was a result of axonal regeneration at the lesion site or whether it was associated to recovery of autonomous function below the lesion. We retransected the lesion site 8 days after the first transection, which generated a loss of recovered locomotor function $(P<0.001$, Figure $1 \mathrm{~d})$. The BBB score dropped to zero and remained at this level for $>2$ weeks. These findings suggest that functional recovery observed in the Gal-1-treated group was most likely caused by axonal regeneration across the lesion site rather than a compensatory response below the site.

Early Gal-1 treatment leads to reduced scar formation and microglial-astroglial deactivation. Treatment with Gal-1 induced a dose-dependent decrease in scar size in both WT and $\mathrm{Lgals}^{-1-}$ mice. In contrast, vehicle-treated WT mice showed a significant but limited reduction in scar size, which was absent in vehicle-treated $L$ gals $1^{-/-}$mice $(P<0.001, P<0.01$, Figure 2a). Illustrating this phenomenon, a computer-generated image showed the lesion site in red due to an increased number of pixels on blue background as a consequence of inflammation.

Glial scar formation is in part dependent upon the postinjury inflammatory response, including the contribution of rapidly dividing activated microglia, blood-derived macrophages and reactive astrocytes, although it also relies on the degree of cell death at the lesion site. ${ }^{23-27}$ Given the relevance of this response in the recovery of locomotor functions, we analyzed the expression of ED1 (a marker of activated microglia), glial fibrillary acidic protein (GFAP; an astrocyte marker) and nestin (a marker of reactive astrocytes) on spinal cord sections from Gal-1-treated $L$ gals $1^{-/}$mice. Gal-1 treatment induced no significant changes in the number of ED1-positive cells at the lesion site (Figure 2b). However, a strong decrease was observed in the surrounding lesion area in mice treated with 0.5 or $1 \mu \mathrm{g} / \mu \mathrm{l} \mathrm{Gal}-1$, suggesting a less aggressive post-injury inflammatory response. Of note, destruction of downstream tissue in the spinal cord treated with vehicle control was only observed in $L$ gals $1^{-/-}$mice, whereas expression of ED1 could only be detected in the upstream area.

No significant increase in GFAP-positive cells was observed in laminectomy areas under control conditions (data not shown). However, Gal-1 treatment induced profound changes in the phenotype of GFAP-positive cells. Reexpression of nestin intermediate filaments was observed in reactive astrocytes, ${ }^{28}$ which were selectively distributed in areas surrounding the lesion but not in the lesion itself. Gal-1 treatment induced sharp alterations in the morphology of nestin-positive cells, revealing a strong reduction in cellular processes. Quantitative support was obtained through the a

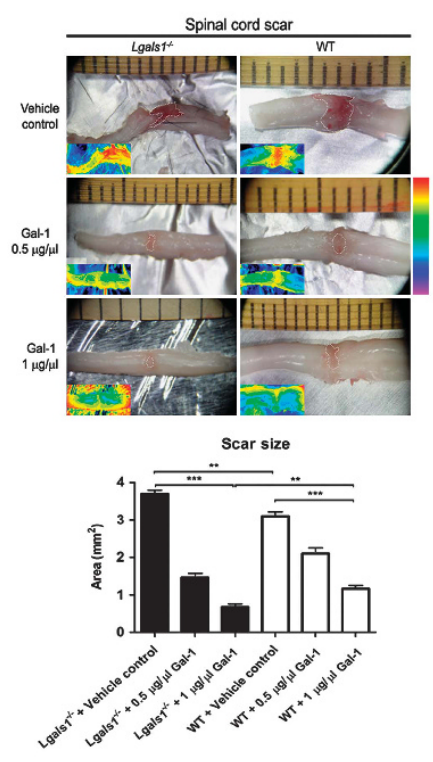

b

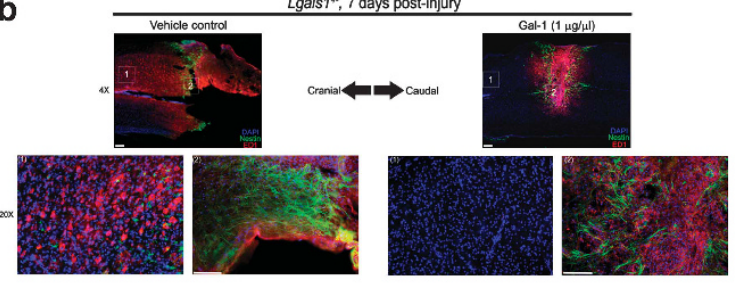

c

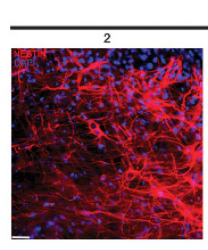

Projection $z$

d

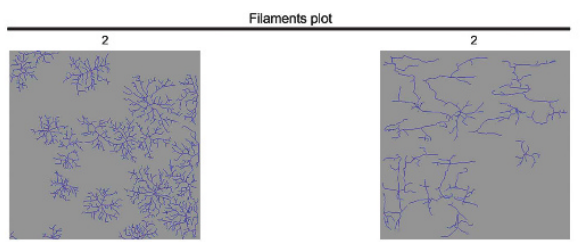

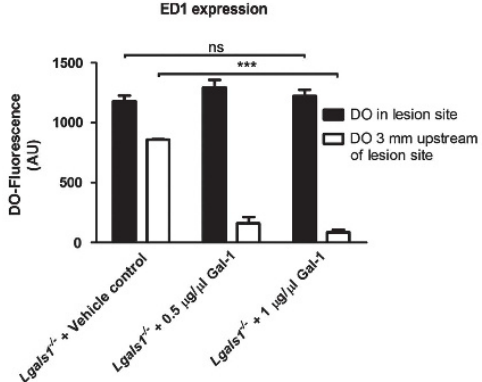

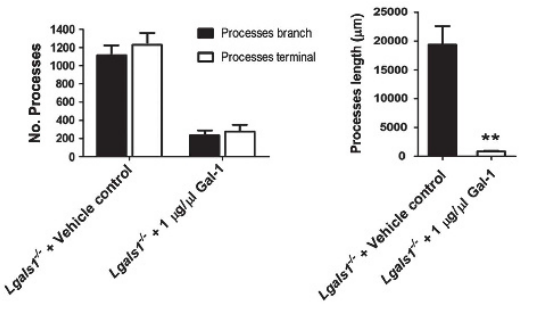

Figure 2 Evaluation of scar size and microglial-astroglial response induced by Gal-1. In all representative images, the left side is cranial. (a) Spinal cord scar size in 0.5 or $1 \mu \mathrm{g} / \mu \mathrm{l}$ Gal-1-treated-Lgals $1^{-/-}$and WT mice. Pictures show scar localization delimited by white dotted line. Also, in the bottom left corner of each picture, a spectrum graph generated with the Lut function of Fiji image processing software emphasizes higher signal in red and lower signal in blue. Calibration is shown on the right band (0-255 colors). Quantitative analysis is shown in bar graph below. Values represent the mean \pm S.D. of seven independent experiments $\left(n=3\right.$ mice per group). ${ }^{* \star *} P<0.001$, ${ }^{* *} P<0.01$ using one-way ANOVA followed by Tukey's tests. (b) Triple staining shows expression of ED1 and nestin at the lesion site and gray matter (dotted frames 1 and 2 ) with vehicle or $1 \mu \mathrm{g} / \mu \mathrm{l} \mathrm{Gal-1}$ (counterstained with DAPI (4,6-diamidino-2-phenylindole)). Scale bars: $250 \mu \mathrm{m}$ for $\times 4 ; 150 \mu \mathrm{m}$ for $\times 20$. Quantitative analysis is shown in the right bar graph. Values represent the mean \pm S.D. of six independent experiments $\left(n=3\right.$ mice per group). ${ }^{* \star \star} P<0.001$, NS $=$ not significant, using one-way ANOVA followed by Tukey's tests. (c) The figure shows the Z-projection image of nestin-positive cells at the lesion site (dotted frame 2), acquired using confocal Z-reconstruction microscopy. Scale bar, $50 \mu \mathrm{m}$. (d) Filament plot was performed for each image, and quantification is shown on the right bar graph. Values represent the mean \pm S.D. of six independent experiments ( $n=3$ mice per group). ${ }^{* *} P<0.01$ using unpaired $t$-test 
assessment of branches and terminals as well as the length of these processes $(P<0.01$, Figures $2 \mathrm{c}$ and $\mathrm{d})$.

Treatment with Gal-1 enhances regeneration of injured axons. The degree of functional recovery following $\mathrm{SCl}$ depends on the reorganization of neuronal circuits by synaptic plasticity and collateral sprouting of injured and healthy descending tracts. ${ }^{29,30}$ To examine the effect of Gal-1 treatment in the regeneration of injured axons, we performed immunohistochemical analysis using the specific neuronal marker $\beta$ III-tubulin and the axonal markers Neurofilament-M (NF-M) and axonal microtubule-stabilizing protein Tau-1. ${ }^{31}$ The grey matter of vehicle-treated $L$ gals $1^{-1-}$ mice exhibited no neurite regeneration at the epicenter of the lesion site (Figure $3 \mathrm{a}$ ) and evidenced no significant differences with vehicle-treated WT mice, suggesting that endogenous Gal-1 did not induce neurite regeneration. In contrast, Gal-1-treated Lgals $1^{-1-}$ mice exhibited a significant and dose-dependent increase in the regenerated area of the lesion (0.8 and $1 \mathrm{~mm}^{2}$ using 0.5 and $1 \mu \mathrm{g} / \mu \mathrm{l} \mathrm{Gal}-1$, respectively) as compared with vehicle-treated Lgals $1^{-1-}$ mice $(P<0.001$, Figures $3 b-d)$. When results were expressed as the percentage of neurite regeneration, only Gal-1-treated animals exhibited a significant increase (67 and $73 \%$, using 0.5 and $1 \mu \mathrm{g} / \mu \mathrm{l}$ Gal-1, respectively) at the lesion site (Figure $3 e$ ). Interestingly, in the upstream area of Lgals $1^{-1-}$ mice treated with $1 \mu \mathrm{g} / \mu \mathrm{l}$ Gal-1, gray matter occupation by motoneurons reached levels similar to those observed in sham mice (Figure 3f).

When the downstream area was analyzed, the motoneurons in gray matter were more preserved in $L$ gals $1^{-1-}$ mice treated with $1 \mu \mathrm{g} / \mu \mathrm{l} \mathrm{Gal}-1$, as compared with vehicle-treatedLgals $1^{-1-}$ mice, almost reaching sham levels. In this area, a significant number of motoneurons was observed in vehicletreated WT mice relative to vehicle-treated $L g a l s 1^{-1-}$ mice, suggesting the activation of a homeostatic circuit triggered by endogenous Gal-1 (Supplementary Figure S4). To further characterize motor circuits, we performed a retrograde tracing

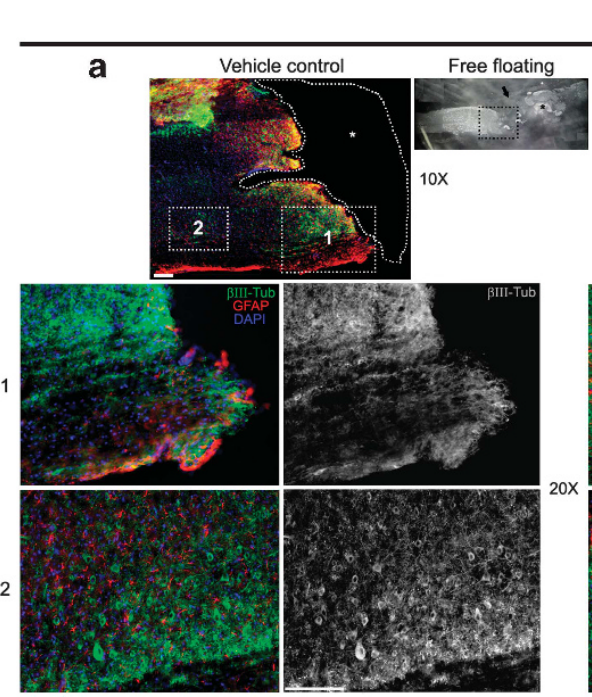

Lgals $1^{-,}, 7$ days post-injury

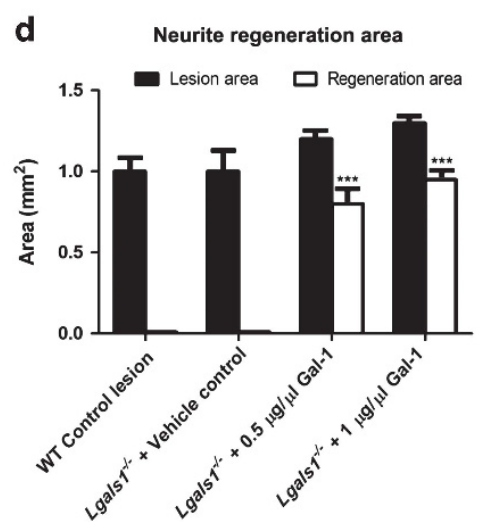

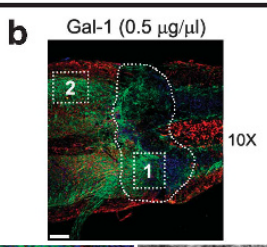
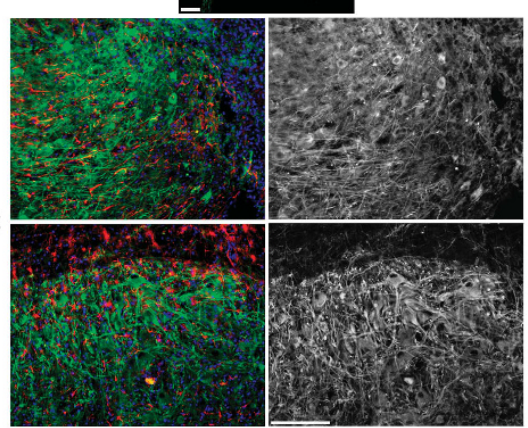

e

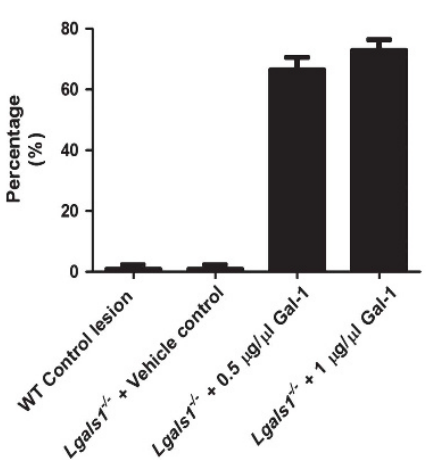

c
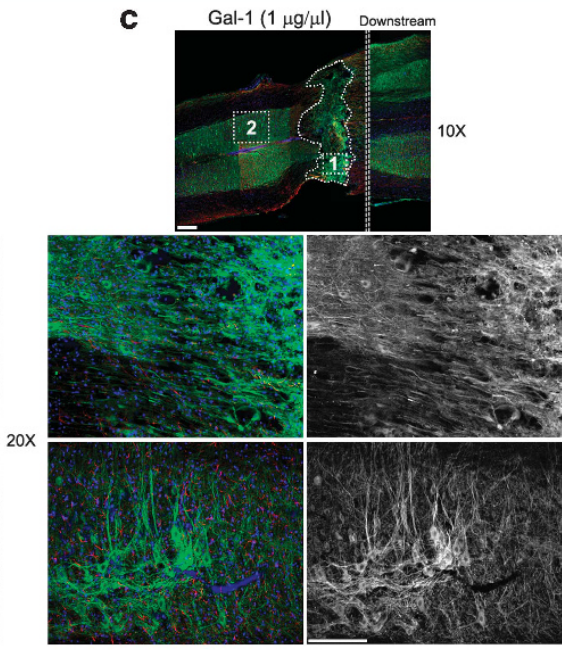
Percentage of gray matter area occupied
by motoneurons upstream of lesion site

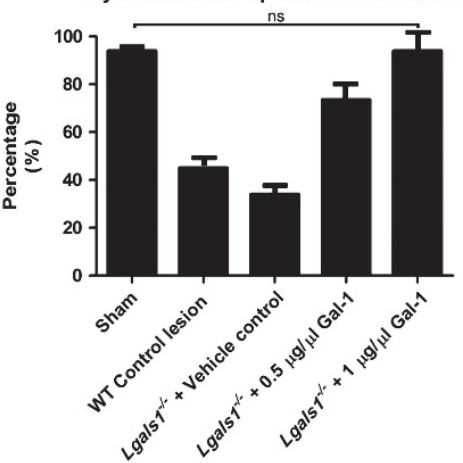

Figure 3 Neurite regeneration induced by Gal-1. In all representative images, the left side is cranial. (a) Triple staining in spinal cord from mice treated with vehicle at the lesion site (dotted line area marked by an asterisk) with $\beta$ III-tubulin, GFAP and DAPI (4,6-diamidino-2-phenylindole). The free floating inset shown in the right picture highlights the lesion site (black arrow) and the loss of downstream tissue (black asterisk). Images below correspond to magnification of dotted frames of lesion site and gray matter

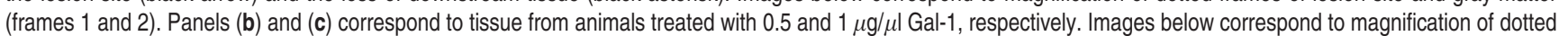
frames 1 and 2. Scale bars: $250 \mu \mathrm{m}$ for $\times 10 ; 150 \mu \mathrm{m}$ for $\times 20$. (d and e) Bar graphs show quantification of neurite regeneration areas also depicted as percentage. (f) Bar graph shows quantification of gray matter area occupied by motoneurons upstream of the lesion site. Values represent the mean \pm S.D. of six independent experiments $(n=3$ mice per group). ${ }^{* * *} P<0.001$ using one-way ANOVA followed by Tukey's tests 
assay in which the motor circuits afferent to muscle were analyzed. We confirmed the preservation of lumbar motoneurons and their functional axons in Gal-1-treated Lgals $1^{-1-}$ mice as cholera toxin $\beta$-subunit (CTB) label cells directly projecting to muscle (Figure 4).

When the number of regenerated axons was analyzed at the epicenter of the lesion site, we only found a few fragments of neurofilament-positive axons in vehicle-treated $\operatorname{Lgals1^{-/-}}$ mice. In contrast, we observed a significant increase in neurofilament-positive axons as well as an increase in Tau-1 expression in Gal-1-treated Lgals $1^{-1-}$ mice $(P<0.001$, Figures $5 a-c)$. Importantly, we only found downstream tissue degeneration in vehicle-treated $\operatorname{Lgals1^{-1}-}$ mice.

Assessment of regeneration in the white matter showed that treatment of $\mathrm{Lgals}^{-/}$mice with Gal-1 induced an increase in the percentage of the area occupied by $\beta$ IIItubulin-positive axons (see Figures $6 a$ and c). Accordingly, a dose-dependent increase in the number of regenerated NFM-positive axons was observed in $L$ gals $1^{-1}$ mice treated with Gal-1 as compared with vehicle-treated $L g a l s 1^{-/}$mice ( $P 0.02, P<0.001$, Figures $6 \mathrm{~b}$ and $\mathrm{d}$ ). Of note, no significant differences were observed between $\operatorname{Lgals} 1^{-1}$ mice treated with the highest dose of Gal-1 and sham $\operatorname{Lgals1^{-1}-}$ mice. Collectively, these results indicate substantial axonal regeneration induced by Gal-1 in descending and ascending tracts of the lesion site.
Gal-1 inhibits Sema3A binding to the NRP-1-PlexinA4 complex. To gain insight into the molecular mechanisms underlying this neuroregenerative effect, we hypothesized that Gal-1 could bind to NRP-1-PlexinA4 (Sema3A-complex receptor) and interfere with Sema3A binding, thus blocking its inhibitory effect on axonal regeneration. Longitudinal slices $(30 \mu \mathrm{m})$ obtained from $\operatorname{Lgals} 1^{-1-}$ mice treated with Gal-1 or vehicle control were incubated in vitro with Gal-1 or with biotin-tagged Gal-1 $(50 \mu \mathrm{M})$. In these slices, we assessed cellular distribution of NRP-1, Gal-1 and Sema3A (Figure 7). Upstream of the lesion, a motoneuron phenotypically normal showed that NRP-1 flanked axonal growth. NRP-1 accumulation is indicated by yellow arrows, while axonal growth is depicted with a white dotted line towards white matter (yellow asterisk). In the area adjacent to the lesion - above the yellow dotted line - a neuron is shown where Gal-1 is absent, showing NRP-1 accumulation close to the axon and blocking cone growth (yellow arrows). On the opposite side, ectopic and truncated sprouting indicates failure of regeneration (blue arrow). This sprouting effect was in agreement with studies where lesioned neurons were capable, depending on environmental cues, of regenerating axon-like structures, even from pre-existing dendrites opposing the original axon. ${ }^{32-34}$ In contrast, the lesion area showed neurons with considerable uptake of exogenous Gal-1 accompanied by spread of NRP-1 and axonal

Lgals $1^{\%}, 3$ days post-retrograde tracer injection

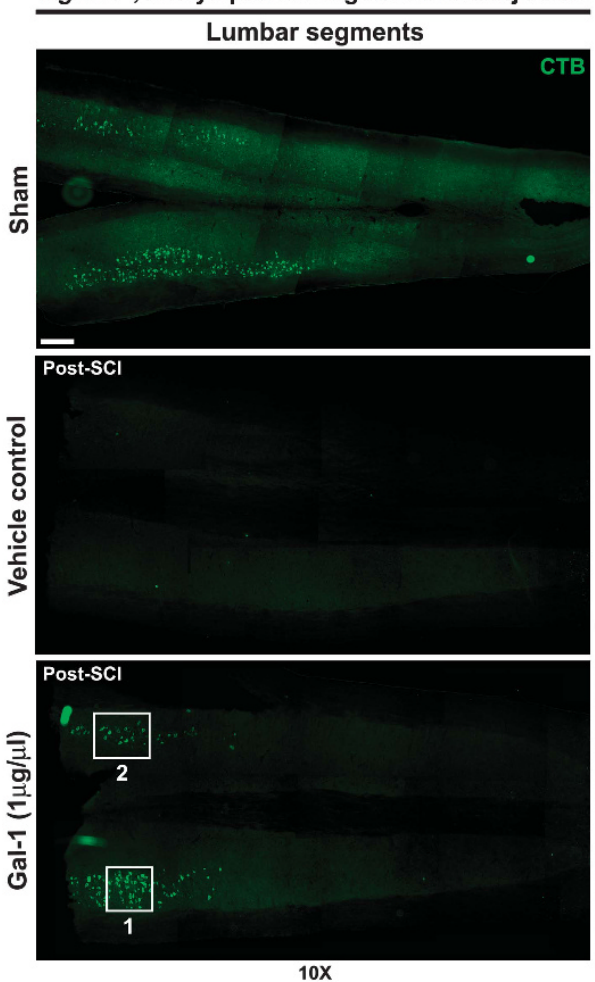
bar segments
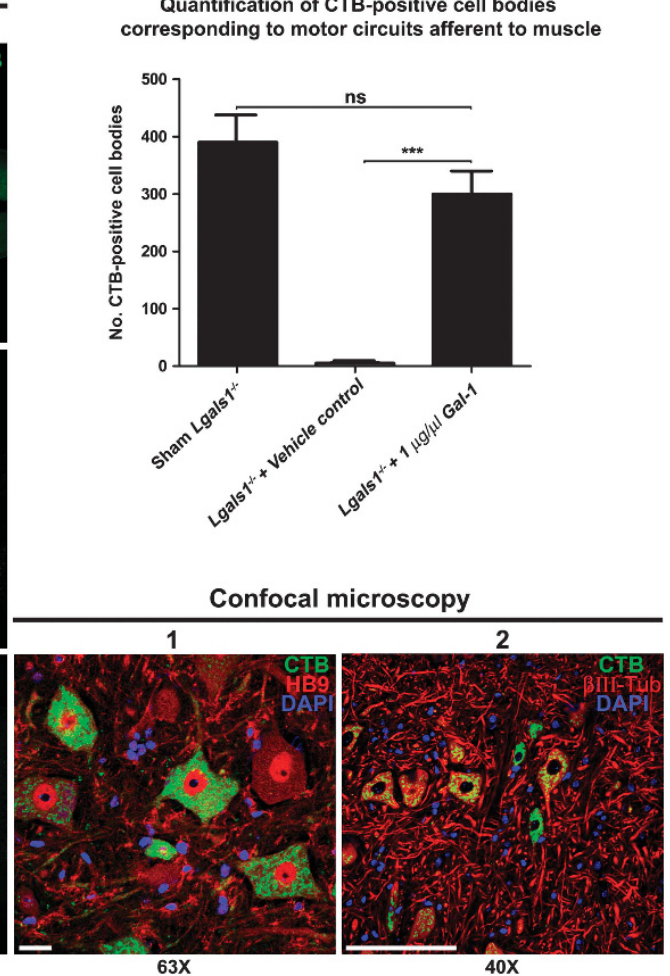

Figure 4 Quantification of CTB-positive cell bodies corresponding to motor circuits afferent to the muscle. Vehicle- and Gal-1-treated $L g a l s 1^{-/-}$mice showed SCI followed by axonal tracing with CTB-Alexa 488 injections into the gastrocnemius muscle/sciatic nerve site. The left panels are representative images taken from the lumbar section, where the left side is cranial. The bar graph shows the number of motoneurons in each group that uptake CTB. Values represent the mean \pm S.D. of four independent experiments ( $n=3$ mice per group). ${ }^{* * \star} P<0.001$ and NS $=$ not significant using one-way ANOVA followed by Tukey's tests. The bottom right panels 1 and 2 show a confocal magnification of CTB-positive cell bodies from Gal-1-treated Lgals $1^{-1}$ mice with a specific motoneuron marker, HB9, and specific neuronal marker, $\beta \| I-$-tubulin. Scale bars: $250 \mu \mathrm{m}$ for $\times 10 ; 100 \mu \mathrm{m}$ for $\times 40.20 \mu \mathrm{m}$ for $63 X$ 
a $\quad L g a / s 1^{1-}, 7$ days post-injury
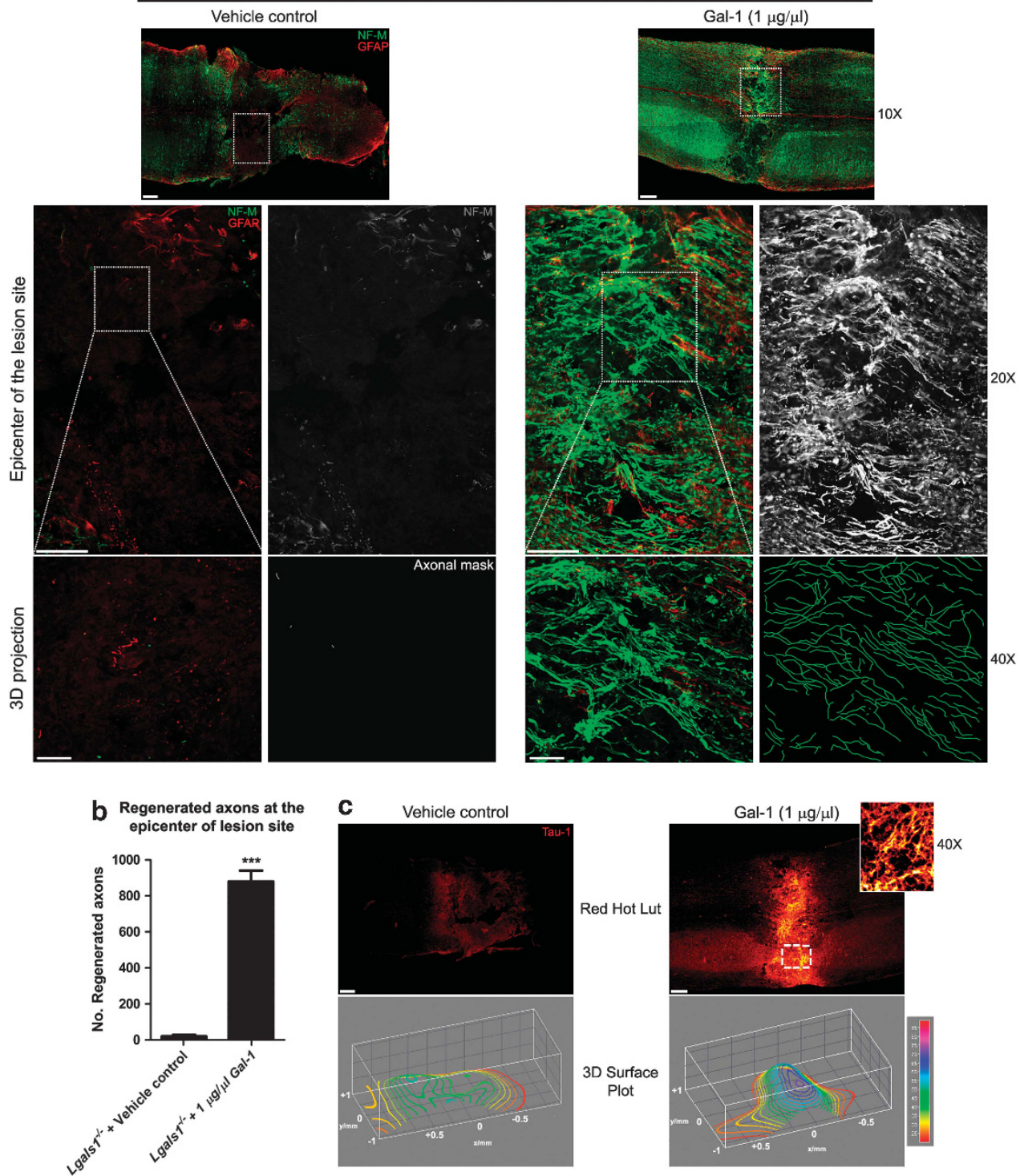

Figure 5 Quantification of neurofilament-positive axons and Tau-1 expression in Gal-1-treated Lgals $1^{-1-}$ mice. In all representative images, the left side is cranial. (a) Double staining, in spinal cord from mice treated with vehicle or Gal-1 at the lesion site, with NF-M and GFAP. Figures below correspond to magnification of dotted frames at the epicenter of lesion site. 3D projection corresponds to confocal $z$-series. The axonal mask was performed using Neuron J plug-in from Fiji program. (b) Bar graph shows the number of regenerated axons at the epicenter of the lesion site. Values represent the mean \pm S.D. of five independent experiments $\left(n=3\right.$ mice per group). ${ }^{* \star *} P<0.001$ using unpaired $t$-test. (c) Single staining with Tau-1. The image shows the expression of Tau-1 at the epicenter of lesion site; the inset shows magnification of the white dotted frame. The expression analysis was performed using 3D surface plot plug-in from Fiji program. Scale bars: $250 \mu \mathrm{m}$ for $\times 10$; $150 \mu \mathrm{m}$ for $\times 20 ; 50 \mu \mathrm{m}$ for $\times 40$

regeneration (yellow arrows) (Figure 7a). A computergenerated 3-D image, obtained from Z-stack scanning of cells immunostained for Gal-1 and NRP-1, showed that Gal-1 bound to the surface of injured neurons. In addition, a quantitative correlation analysis using Mander's algorithm showed that $75 \%$ NRP-1 clusters had, in turn, a Gal-1 cluster in the vicinity of their focal plane and that their colocalization rate was almost $50 \%$ (Figure $7 \mathrm{~b}$ ).

To evaluate the ability of Gal-1 to interrupt the Sema3A pathway, we compared Sema3A immunoreactivity in the lesion area of vehicle- or Gal-1-treated-Lgals $1^{-1-}$ mice. More than $80 \%$ Sema3A immunoreactivity was observed adjacent to the lesion site in neurons of vehicle-treated-Lgals $1^{-/-}$ mice, which showed truncated axons (thick blue arrows) (Figure 7c). Strikingly, as a result of Gal-1 treatment, $\sim 80 \%$ of neurons showing high Gal-1 uptake (yellow arrows) and axon regeneration (white dotted line) showed no Sema3A uptake. Interestingly, the area inside the lesion without cellular bodies (indicated by a yellow asterisk) was surrounded by truncated axons (thin blue arrows) with Sema3A immunoreactivity and absence of Gal-1 uptake. Of note, a $\beta$ III-tubulin immunoreactive neuron body showing non-regenerated axons (thick blue arrow) co-localized with Sema3A (Figure 7c). Furthermore, immunoreactivity of the Sema3A-coreceptor PlexinA4 and its co-localization with Gal-1 and $\beta$ III-tubulin were evaluated in longitudinal slices from $L g a l s 1^{-1-}$ mice treated 
a Lgals ${ }^{1-}, 7$ days post-injury

\begin{tabular}{lccc}
\hline Sham & Vehicle control & Gal-1 $(0.5 \mu \mathrm{g} / \mu \mathrm{l})$ & Gal-1 $(1 \mu \mathrm{g} / \mu \mathrm{l})$ \\
& & & \\
& & & \\
& & &
\end{tabular}
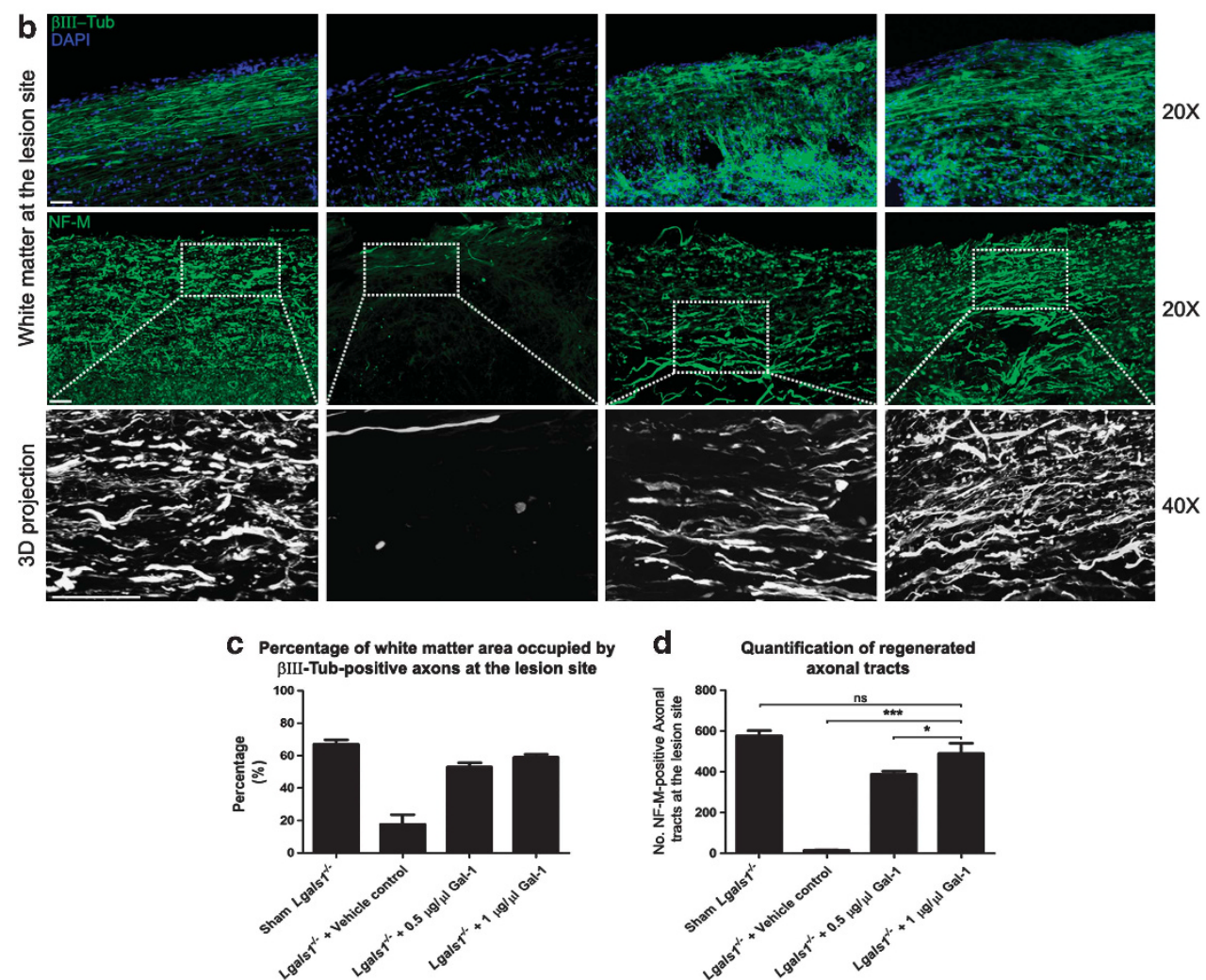

Figure 6 White matter axonal regeneration at the lesion site in $L$ gals $1^{-/}$mice treated with Gal-1. In all representative images, the left side is cranial. (a) Double staining with $\beta$ III-tubulin and DAPI (4,6-diamidino-2-phenylindole). Left figure corresponds to sham mice and shows white matter area occupied by axons. The following figures display changes in the area occupied by regenerated axons in white matter at the lesion site in vehicle- or Gal-1-treated-Lgals $1^{-/-}$mice. (b) Single staining with NF-M. 3D projection corresponds to confocal $z$-series. (c) Bar graph shows the percentage of white matter area occupied by $\beta \| l$-tubulin-positive axons at the lesion site. (d) Bar graph shows quantification of regenerated NF-M-positive axonal tracts. Values represent the mean \pm S.D. of seven independent experiments $\left(n=3\right.$ mice per group). ${ }^{* \star \star} P<0.001$, ${ }^{*} P=0.0277, \mathrm{NS}=$ not significant, using one-way ANOVA followed by Tukey's tests. Scale bars: $1 \mathrm{~mm}$ for $\times 4 ; 50 \mu \mathrm{m}$ for $\times 20 ; 100 \mu \mathrm{m}$ for $\times 40$

with $1 \mu \mathrm{g} / \mu \mathrm{l} \mathrm{Gal}-1$. As shown in the 3-D image, Gal-1 bound to the surface of injured neurons. In addition, a quantitative correlation analysis using Mander's algorithm showed similar results to those corresponding to NRP-1 (Supplementary Figure S5). These results suggest that Gal-1 can interact with the receptor NRP-1-PlexinA4 complex and displaces Sema3A binding.

A monomeric Gal-1 mutant (M-Gal-1) induces neuroprotection through microglial deactivation but fails to induce neuroregeneration. Given the different biological activities of monomeric versus dimeric Gal-1 species, we used a Gal-1 mutant (M-Gal-1), which exists in a monomeric form even at high concentrations. ${ }^{35} \mathrm{M}-\mathrm{Gal}-1$ treatment in Lgals $1^{-1-}$ mice induced a similar locomotor behavior than treatment with vehicle control in WT mice showing a BBB score of $\sim 4 \pm 0.49$ (Supplementary Figure S6a). Both groups evidenced a limited capacity to keep on the top of the bridge-shaped metal grid by balancing on their front limbs, with little use of their tails and no involvement of their hindlimbs (Supplementary Figures S6b-e). Moreover, these mice had a significantly higher but limited BBB score compared with that of vehicle-treated Lgals $1^{-1-}$ mice and strikingly lower than the BBB score attained in Gal-1-treated Lgals $1^{-1-}$ mice (16 \pm 0.7$)$.

In agreement with these findings, M-Gal-1 induced a significant reduction in scar size compared with treatment with vehicle control, although slighter than that induced by WT Gal-1 (Supplementary Figure S7). Concomitantly, when ED1positive cells were evaluated, treatment with M-Gal-1 induced no significant changes at the lesion site but a significant decrease in the upstream and downstream areas (Figure 8a). Interestingly, the decrease induced by M-Gal-1 was lower in the downstream than in the upstream area, suggesting different capacities of monomeric versus dimeric forms of this lectin to deactivate microglia. Moreover, M-Gal-1-treatedLgals $1^{-/-}$mice displayed higher nestin immunoreactivity with greater process arborization as compared with Gal-1treated $L$ gals $1^{-1-}$ mice. These results were quantitatively supported by the evaluation of branches, terminals and length 
a $\operatorname{Lgal} / 1^{1-}, 7$ days post-injury with Gal-1 treatment
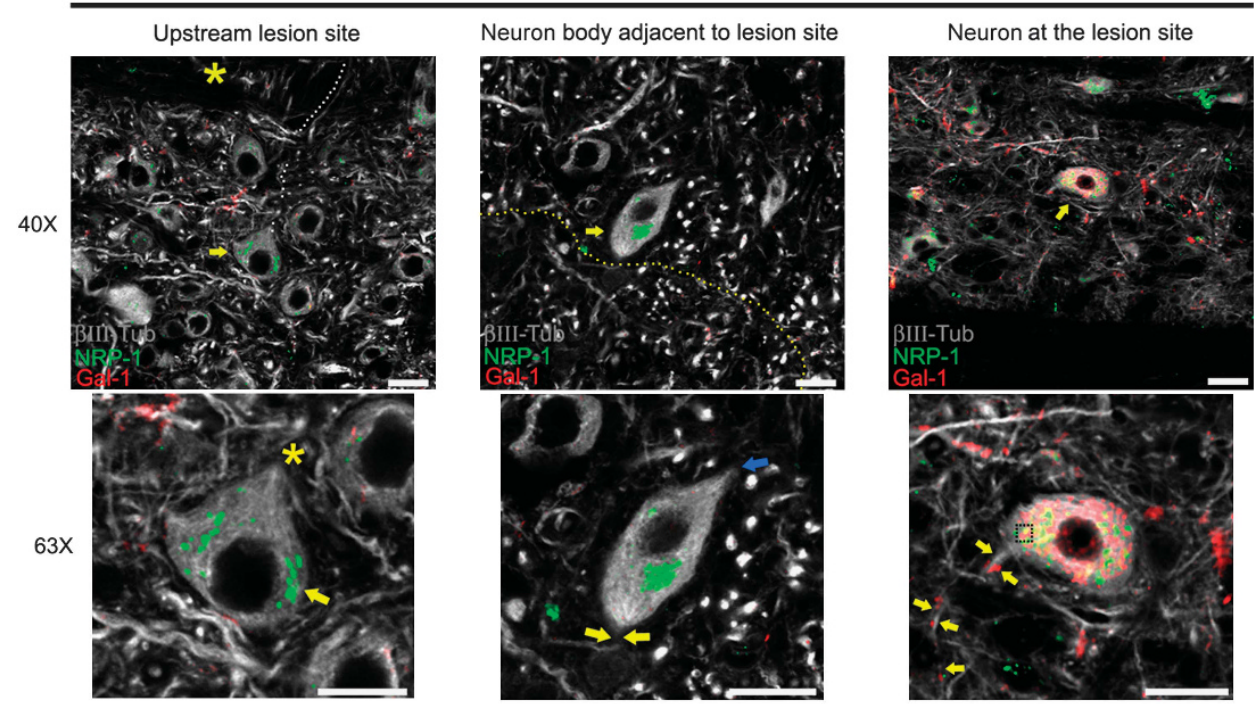

b

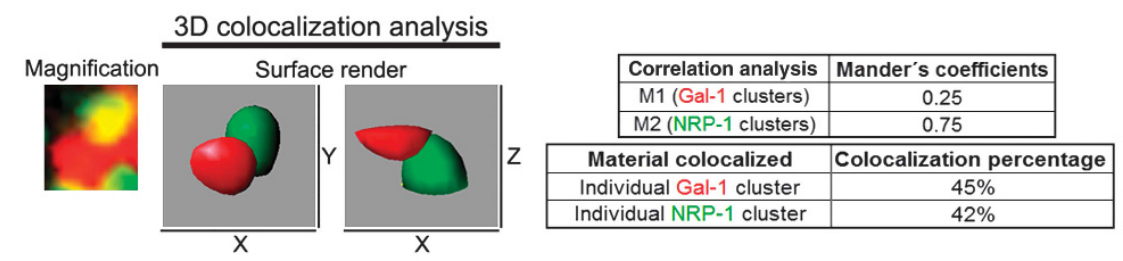

c Lgals $1 \%, 7$ days post-injury
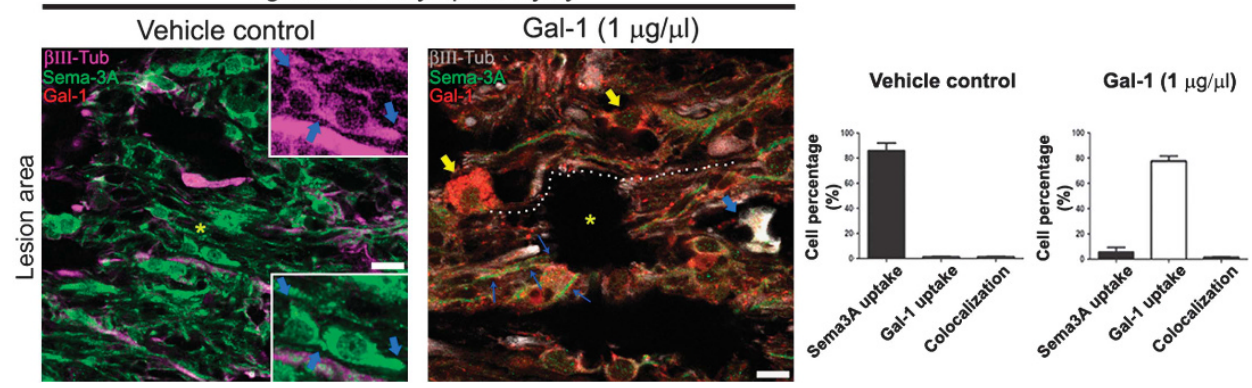

Figure 7 Localization of NRP-1, Gal-1 and Sema3A in neurons from vehicle- or Gal-1-treated-Lgals $1^{-1-}$ mice. (a) Confocal representative images showing neurons in three different areas of the spinal cord and in different magnification ( $\times 40$ in top panel and $\times 63$ in bottom panel). (b) Figure shows a computer-generated 3D image of NRP-1 (green) and Gal-1 (red) clusters localized on the neuron body (dotted black frame in $\times 63$ right image of panel (a). The right panel shows a quantitative correlation analysis using Mander's algorithm, as well as a quantitative colocalization rate analysis. Data are representative of four independent experiments $(n=3$ mice per group). (c) A representative triple staining with $\beta$ III-tubulin, Sema3A and Gal-1 shows neurons in the lesion area in vehicle- (left) or Gal-1-treated $L g a l s 1^{-/-}$mice (right). The quantification is shown in the bar graphs on the right. Values represent the mean \pm S.D. of five independent experiments $(n=3$ mice per group). Scale bar, $20 \mu \mathrm{m}$

of processes (Figures $8 \mathrm{~b}$ and $\mathrm{c}$ ). We evaluated the neurite regeneration induced by $\mathrm{M}-\mathrm{Gal}-1$ using $\beta$ III-tubulin as a specific marker (Figure 8d). In contrast to the sharp regenerative effect obtained with WT Gal-1, M-Gal-1 did not induce neuroregeneration, as no immunoreactive staining was detected for $\beta$ III-tubulin at the epicenter of lesion site (Figure 8e). On the other hand, both upstream and downstream areas (Figures $8 f$ and g) displayed $\beta$ III-tubulin-positive motoneurons with normal phenotype, similar to those observed with WT Gal-1, which could be the result of deactivation of microglia. When the percentage of descending/ ascending axons in the white matter at the lesion site was evaluated (Figure 8h), a significant decrease was observed when treatment was performed with M-Gal-1 as compared with the WT lectin. These results are similar to the findings observed after treatment with vehicle control. These results suggest that M-Gal-1 has no significant capacity to induce axonal regeneration. Additionally, cellular distribution of NRP-1 in the lesion area of M-Gal-1-treated mice was evaluated. Surprisingly, Gal-1 immunoreactivity was not observed in these samples, indicating that M-Gal-1 has no ability to bind neuronal targets. Moreover, M-Gal-1-treated lesions showed neurons with NRP-1 accumulation close to truncated axons (yellow arrows) (Figure 8i).

To further confirm these interactions at the biochemical level, immunoprecipitation assays were performed with total cell lysates obtained from the lesion site (plus $1 \mathrm{~mm}$ up and

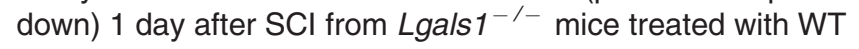


or M-Gal-1. NRP-1-immunoprecipitates obtained from Gal-1treated-Lgals $1^{-/-}$mice showed the presence of immunoreactive bands for NRP-1 (only when NRP-1 antibody was used) and Sema3A-co-receptor PlexinA4, which suggests that the whole Sema3A receptor complex was pulled down. Remarkably, these immunoprecipitates were also positive for Gal-1, supporting the formation of a Gal-1-NRP-1/PlexinA4 complex during neuroregeneration (Figure 9a). However, immunoprecipitates from M-Gal-1-treated mice showed positive immunoreactivity only for Sema3A but not for Gal-1 (Figure 9b). These results indicate that Gal-1 in its monomeric form has no capacity to interfere with Sema3A binding to the NRP-1-PlexinA4 complex. To further evaluate whether Gal-1 binding to NRP-1 involves glycosylation-dependent interactions, we performed similar experiments using NRP-1immunoprecipitated lysates purified from Gal-1-treated Lgals 1-/- mice following incubation with PNGase-F to release $\mathrm{N}$-glycans. Results showed the appearance of a new $105 \mathrm{kDa}$ protein band corresponding to NRP-1, which could not bind to $\mathrm{Gal}-1$ as a consequence of $N$-glycan removal (Figure 9c).

In order to confirm whether Gal-1 interferes with the interactions between Sema3A and the NRP-1-PlexinA4 complex, we evaluated these molecules in NRP-1 immunoprecipitates from vehicle- and Gal-1-treated $L$ gals $1^{-/}$mice. Quantitative analysis showed a significant decrease in Sema3A binding induced by Gal-1 treatment, while NRP-1 expression remained at the same levels in both conditions (Figure 9d), suggesting that Gal-1 may act by inhibiting Sema3A binding to the NRP-1-PlexinA4 complex. To confirm the specificity of these interactions, we then immunoprecipitated Gal-1 and checked for co-precipitation of NRP-1. Results confirmed Gal-1-NRP-1 interactions, and examination of the whole gel confirmed the absence of other potentially relevant bands (Figure 9e). These results support the role of Gal-1 as one of the main NRP-1 binding partners during axonal regeneration. Notably, the anti-Gal-1 polyclonal antibody recognized a $14.5-\mathrm{kDa}$ protein band corresponding to M-Gal-1, which rules out the possibility that the antibody could not recognize Gal-1 in its monomeric form. As an additional control, immunoreactivity of PlexinA4, Sema3A and NRP-1 antibodies was tested in total cell lysates (Figure 9f). Remarkably, when motor recovery was evaluated following administration of the Gal-1-N46D mutant lacking carbohydrate-binding activity, we found no considerable recovery of the motor function in these mice, which showed a BBB score of $\sim 0$ (Figures 10a-e). These results are in accordance with a complete absence of axonal regeneration and marked Sema3A immunoreactivity in the injured neurons at the lesion site (Figure 10f). Collectively, our data show that WT Gal-1 (which occurs in a dimer-monomer equilibrium) recognizes the NRP-1-PlexinA4 complex through glycan-dependent mechanisms, displaces Sema3A binding and promotes neuroregeneration and repair (Supplementary Figure S8).

\section{Discussion}

The mechanisms underlying full locomotor recovery following $\mathrm{SCl}$ remain poorly understood. We have identified a role for Gal-1 as a novel agent capable of interrupting the Sema3A pathway in vivo by directly binding to the NRP-1/PlexinA4 receptor complex via glycan-dependent mechanisms. Our findings demonstrate that Gal-1 induced full locomotor functional recovery and that an early intervention with this lectin was sufficient to prevent hindlimb loss of function after $\mathrm{SCl}$. These effects were accompanied by a decrease in scar size, reflecting microglial-astroglial deactivation. Recovery was evidenced by determination of BBB locomotor rating scale, where mice treated with Gal-1 reached the late recovery stage (forelimb and hindlimb coordination). These results correlated with a greater number of regenerated axons in the gray matter, as well as striking axonal regeneration in the white matter, within and across the lesion site. Importantly, after $\mathrm{SCl}$, the descendent axonal tracts axotomized expressed NRP-1 and PlexinA4, becoming sensitive to the negative regulatory effects of Sema3A. In this regard, previous studies showed expression of Sema3A within the transected spinal cord that was upregulated at the lesion site, peaking within 1 and 2 weeks after the injury. ${ }^{36}$ Because of these particular kinetics, we propose that Gal-1 treatment should take place within a temporal window where its interactions with the NRP-1/PlexinA4 complex could lead to inhibition of Sema3A binding, allowing axonal regeneration of these tracts.

Although Gal-1 could function through other nonoverlapping mechanisms, it is unlikely that the coordinated locomotor behavior observed was due to long axonal tract regeneration from cortex to the lower motoneuron occurring in such a short time period. The possible mechanism implicated is the arrangement of intraspinal neural circuits by the local axons regenerated most probably from interneurons, which make signal relay and synaptic connections with regenerated descending axonal tracts as previously described. ${ }^{36,37}$ Our findings confirmed preservation of lumbar motoneurons and their functional axons in Gal-1-treated mice. Finally, a compensatory response below the lesion site by these lumbar motoneurons was ruled out by retransection experiments, which demonstrated that the locomotor recovery was dependent on site-specific regeneration.

Most of the neuroprotective effects of Gal- 1 have been attributed to its immunomodulatory activities. ${ }^{13}$ Our recent studies revealed that $\mathrm{Gal}-1$ induces microglia deactivation and prevents inflammation-induced neurodegeneration. ${ }^{20}$ In the present study, we successfully uncoupled the microglial deactivating effect, which was observed using both WT and monomeric Gal-1 from the neuroregenerative effect, which was verified only when high concentrations of WT Gal-1 were used. This data suggest the importance of dimerization in the neuromodulatory functions of Gal-1. Accordingly, treatment with M-Gal-1 induced a poor recovery of locomotor functions and caused only a minor reduction in scar size. When neuronal regeneration was analyzed in the lesion area, M-Gal-1 was unable to promote neuroregeneration. This result is in line with the failure of $\mathrm{M}-\mathrm{Gal}-1$ to interfere with Sema3A binding to the NRP-1-PlexinA4 complex and the glycan-dependent nature of these interactions. M-Gal-1 induced only neuroprotection in the upstream or downstream areas of the lesion, probably as a consequence of microglial deactivation. In agreement, previous reports have demonstrated that oxidized Gal-1 - a form that lacks lectin 
activity - promotes neurite outgrowth ${ }^{38}$ and enhances axonal regeneration in peripheral and central nerves. ${ }^{39-41}$ This axonal regeneration-promoting activity is likely to be paracrine, as neurite outgrowth induced by oxidized Gal-1 is not observed in isolated neurons. ${ }^{42}$ Secreted Gal-1 probably influences non-neuronal cells surrounding the axons, ${ }^{43}$ conferring a neuroprotective effect, such as that observed for M-Gal-1.

Notably, vehicle-treated WT mice reached a BBB score of $\sim 4$ and had significant but limited reduction in scar size, two

a
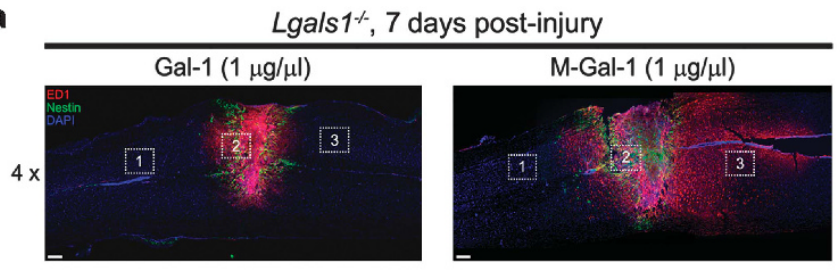

b

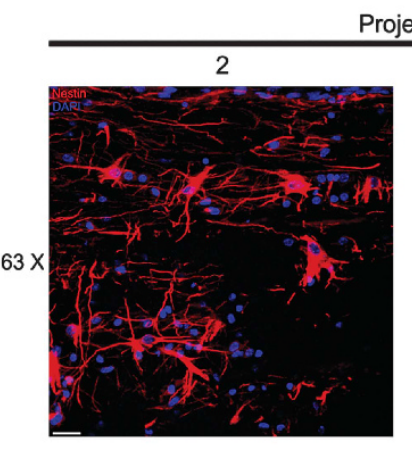

Projection Z

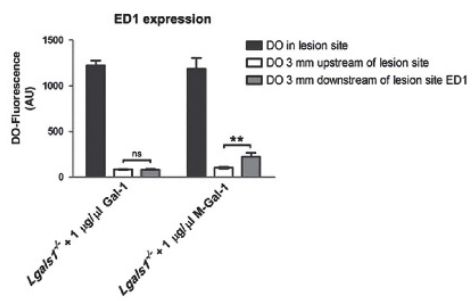

c

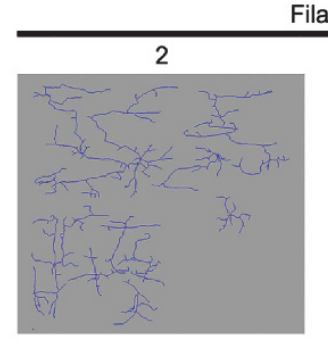

Filaments plot
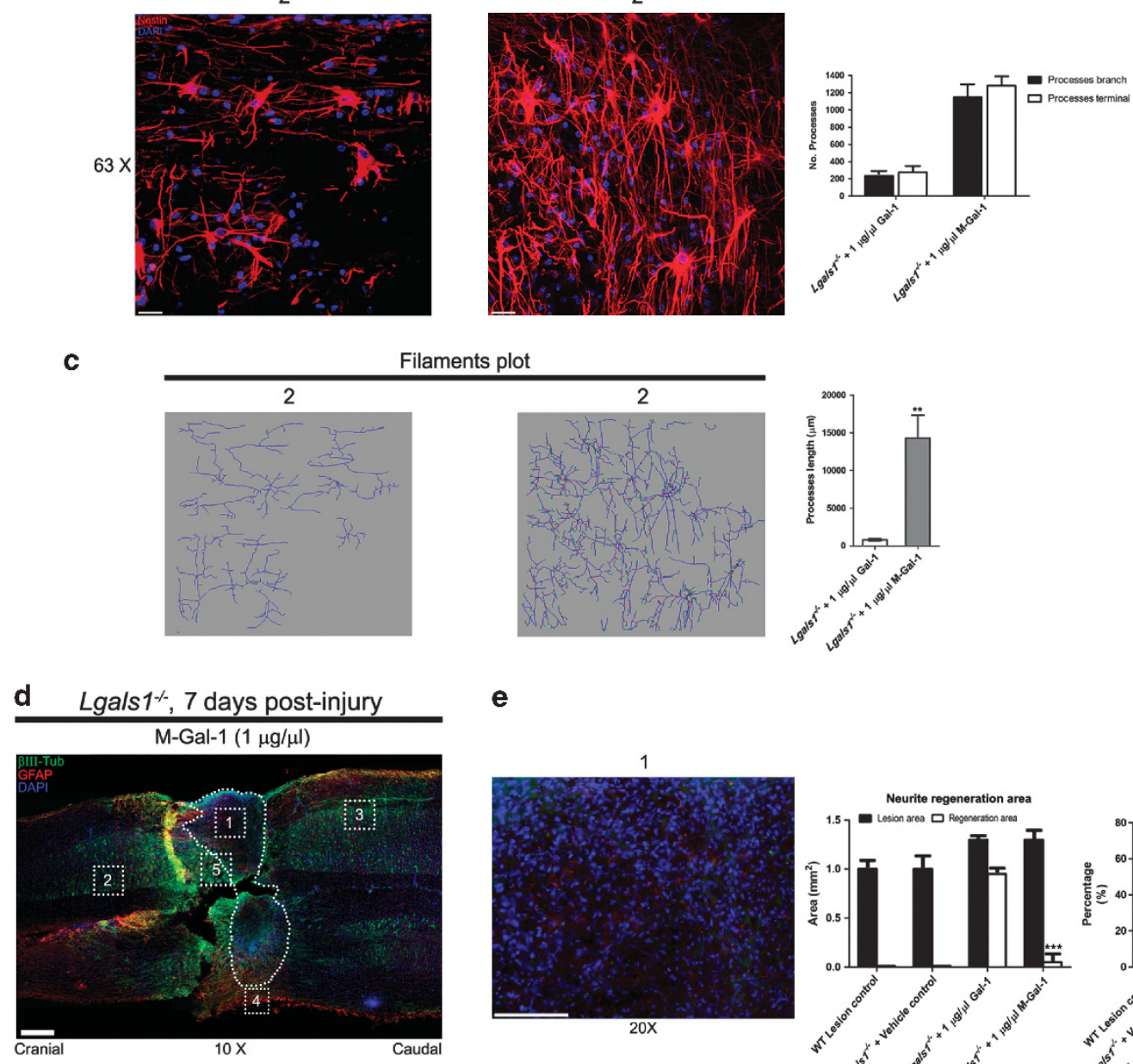

e
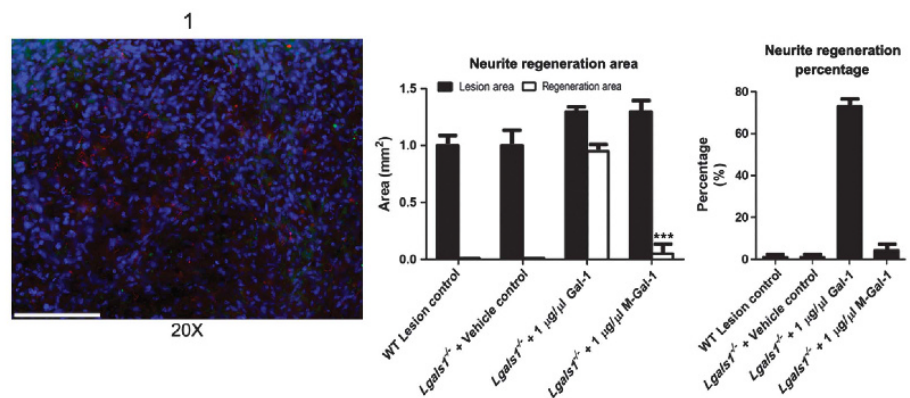

Figure 8 Microglial-astroglial response, neurite regeneration and NRP-1 cellular localization induced by treatment with monomeric Gal-1 (M-Gal-1). In all representative images, the left side is cranial. (a) Triple staining with ED1 and nestin at the lesion site (dotted frame 2) and gray matter (dotted frames 1 and 3) with $1 \mu \mathrm{g} / \mu \mathrm{l}$ of Gal-1 or M-Gal-1 (counterstained with DAPI (4,6-diamidino-2-phenylindole)). Scale bar, $250 \mu \mathrm{m}$. Quantitative analysis is shown in the right bar graph. Values represent the mean \pm S.D. of five independent experiments ( $n=3$ mice per group). ${ }^{\star \star} P<0.01$ using one-way ANOVA followed by Tukey's tests. (b) Figure shows the $Z$-projection image of nestin-positive cells at the lesion site (dotted frame 2 from panel (a), acquired using confocal Z-reconstruction microscopy. Scale bar, $50 \mu \mathrm{m}$. (c) Filament plot was performed, and quantification is shown in the right bar graph. Values represent the mean \pm S.D. of five independent experiments $\left(n=3\right.$ mice per group). ${ }^{\star *} P<0.01$ using unpaired $t$-test. (d) Triple staining with $\beta$ III-tubulin, GFAP and DAPI. Scale bar, $250 \mu \mathrm{m}$. (e-h) The figures are $\times 20$ magnification of frames (1-4) in panel (d). Bar graphs show quantification of regeneration area and percentage of neurite regeneration at the lesion site, percentage of gray matter area occupied by neurons upstream/downstream of the lesion site and white matter percentage occupied by axons as well as axonal regeneration percentage. Values represent the mean \pm S.D. of five independent experiments $(n=3$ mice per group). ${ }_{* * \star} P<0.001$ using one-way ANOVA followed by Tukey's tests. Scale bar, $150 \mu \mathrm{m}$. (i) Triple staining with $\beta$ III-tubulin, NRP-1 and Gal-1 show injured neurons adjacent to the lesion site (marker with yellow \#). Scale bar, $50 \mu \mathrm{m}$ 
f

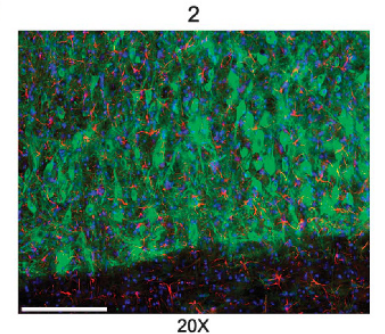

20X

h
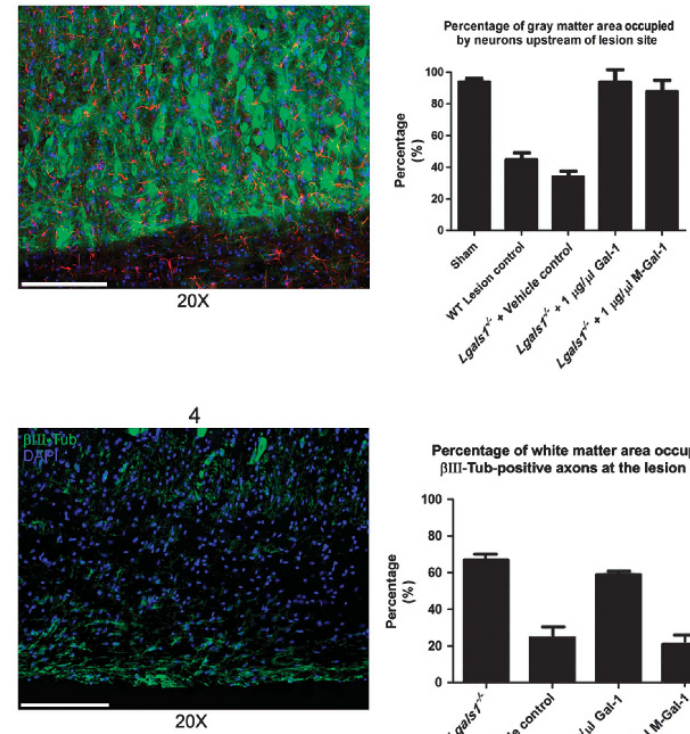

g
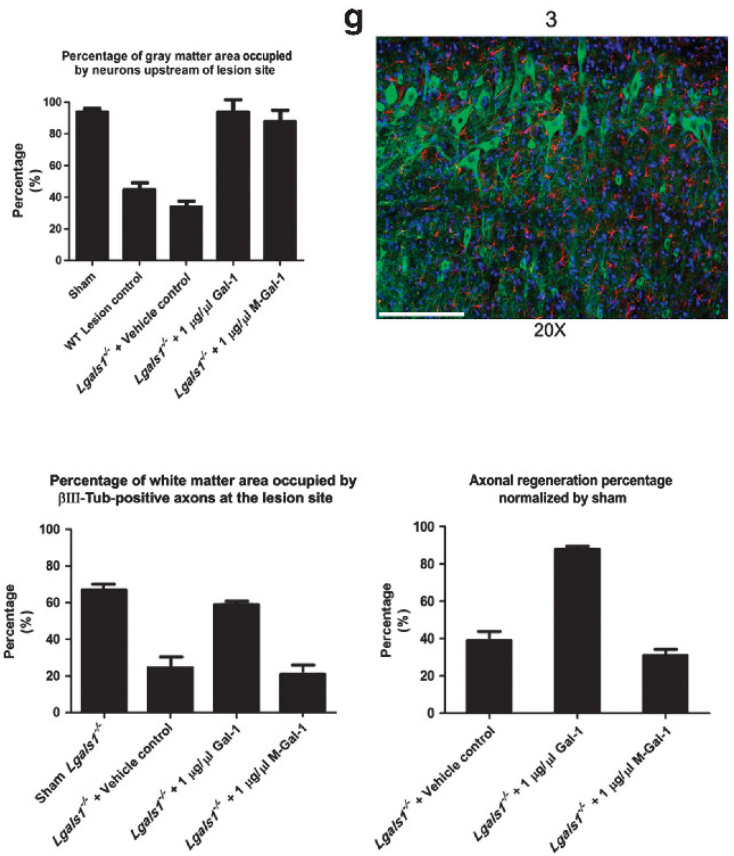

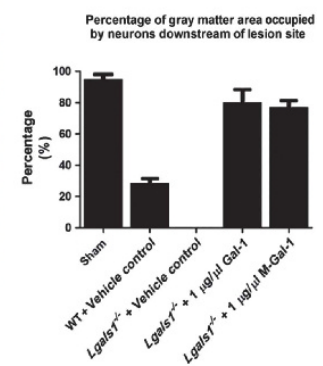

i
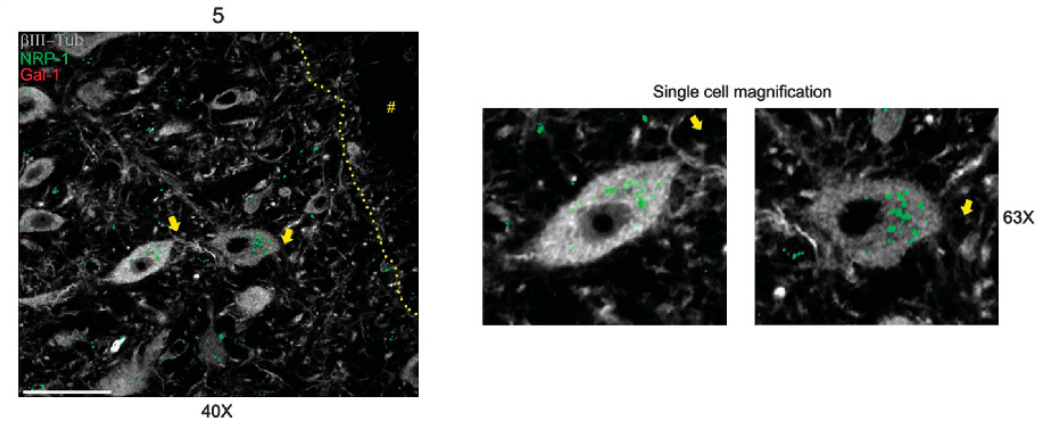

$40 \mathrm{X}$

Figure 8 Continued

signs of partial recovery which were absent in vehicle-treated Lgals $1^{-/-}$mice. This striking finding suggests that endogenous Gal-1 could allow spontaneous although limited motor function recovery following $\mathrm{SCl}$. This notion also arises from the fact that a similar locomotor behavior was obtained in M-Gal-1-treated Lgals $1^{-/-}$mice. Therefore, endogenous Gal-1 could be acting mainly as a monomer, consistent with the physiological concentrations of this lectin, usually $<7 \mu \mathrm{M}$ (the reported dimerization constant). ${ }^{44}$

Gal-1 was previously described as an endogenous ligand for NRP-1 expressed in vascular cells, where it stimulates endothelial cell signaling and function. ${ }^{45}$ Specific carbohydrate-dependent interactions between Gal-1 and NRP-1 have been demonstrated in cell-free systems using surface plasmon resonance analysis. ${ }^{45}$ In our experiments, Gal-1 but not M-Gal-1 or Gal-1 (N46D) lacking carbohydrate-binding activity showed robust capacity to regenerate axons via blockade of Sema3A binding, suggesting that the neuroregenerative effects of this lectin are highly dependent on dimerization and cross-linking of cell surface glycans on NRP-1. This hypothesis was supported by immunoprecipitation experiments showing that only WT Gal-1, but not M-Gal-1, binds to the NRP-1/PlexinA4 complex and blocks the Sema3A pathway. Of note, treatment of NRP-1 immunoprecipitates with PNGase also prevented Gal-1 binding, thus confirming the glycosylation-dependent nature of these interactions. Our functional experiments support the relevance of the carbohydrate recognition domain of this lectin in promoting full locomotor recovery. Future clinical studies should examine the relevance of endogenous Gal-1 in patients with neurological disorders.

The relevance of a regulatory factor such as Gal-1 capable of blocking the Sema3A pathway lies in the fact that it is expressed earlier than other inhibitors previously described, such as Nogo-A, myelin-associated glycoprotein and oligodendrocyte-myelin glycoprotein. ${ }^{2-4,46-49}$ During the past years, different therapies have been proposed that lead to axonal outgrowth after SCI such as SM-216289, ${ }^{36}$ neurotrophic factors, ${ }^{50}$ soluble Nogo receptors, ${ }^{51}$ chondroitinase $\mathrm{ABC}^{49}$ or cellular transplantation. ${ }^{52}$ In particular, SM-216289, a small-molecule inhibitor, showed inhibition of Sema3A functions, including growth cone collapse and chemorepulsion of neurite extension. ${ }^{53,54}$ This compound acted on Sema3A by sterically inducing changes in its structure and hindering binding of NRP-1. Because Gal-1 not only exerts a 

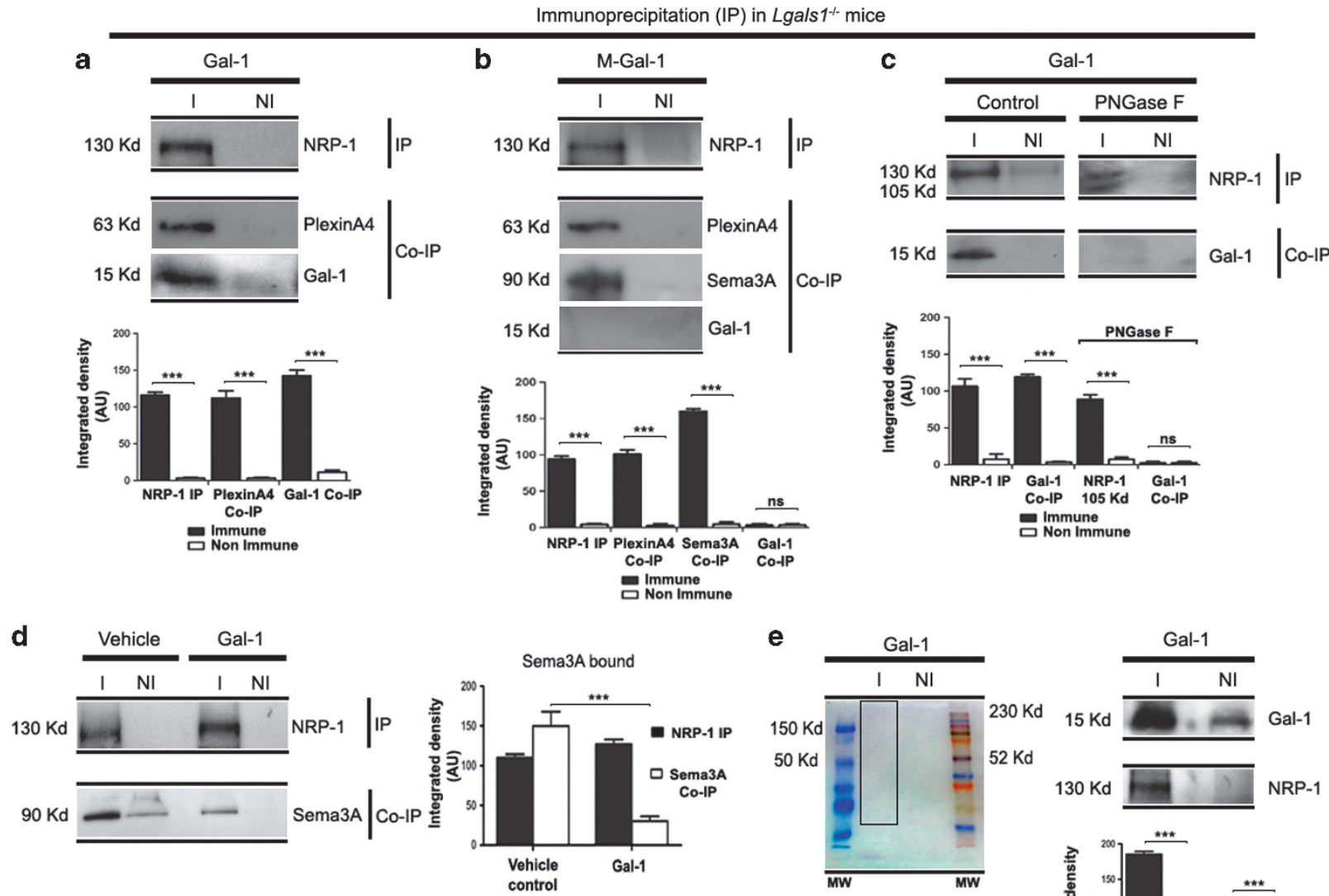

f

Controls

\begin{tabular}{|c|c|c|c|c|}
\hline \multicolumn{2}{|c|}{ Gal-1(R) } & \multicolumn{3}{|c|}{ Lysates } \\
\hline Gal-1 & M-Gal-1 & Total & Total & Total \\
\hline & $\longrightarrow$ & & - & \\
\hline & $\mathrm{al}-1$ & nti-PlexinA4 & Anti-Sema3A & Anti-NRP-1 \\
\hline
\end{tabular}

e

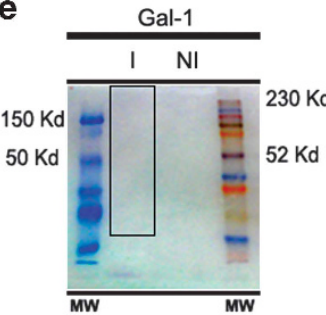

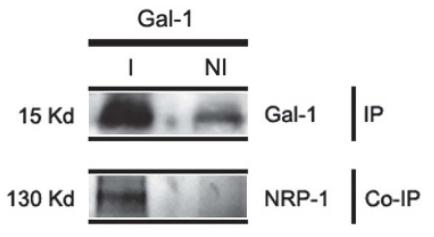

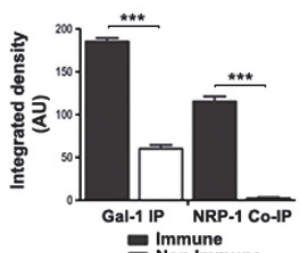

Don Immune

Figure 9 Gal-1 binds to NRP-1 through glycan-dependent interactions. NRP-1 and Gal-1 immunoprecipitation (IP) followed by protein co-IP and western blotting analysis. In all cases, I correspond to immune and NI to non-immune sera. (a and b) Panels show NRP-1 IP of injured spinal cord tissue from Lgals $1^{-/-}$mice treated with $1 \mu \mathrm{g} / \mu \mathrm{l} \mathrm{Gal-1}$ or M-Gal-1, respectively. (c) Panel shows NRP-1 IP following PNGase F treatment to release N-glycans. Values in bar graphs (a-c) represent the mean \pm S.D. of three independent experiments ( $n=3$ mice per group). ${ }^{* *} P<0.001$ using one-way ANOVA followed by Tukey's tests. (d) Panel shows NRP-1 IP and Sema3A co-IP of injured spinal cord tissues from vehicle- or Gal-1-treated-Lgals $1^{-1-}$ mice. The bar graph shows the quantitative analysis of Sema3A uptake. Values represent the mean \pm S.D. of three independent experiments ( $n=3$ mice per group). ${ }^{* \star} P<0.001$ using one-way ANOVA followed by Tukey's tests. (e) Gal- 1 IP of injured spinal cord tissue from $L g a l s 1^{-/-}$ mice treated with $1 \mu \mathrm{g} / \mu \mathrm{l} \mathrm{Gal-1}$. The left panel shows an entire gel (black frame corresponds to immune wells). The right panel shows Gal-1 IP and NRP-1 co-IP. Values in the bar graph below represent the mean \pm S.D. of three independent experiments $\left(n=3\right.$ mice per group). ${ }^{* \star *} P<0.001$ using one-way ANOVA followed by Tukey's tests. (f) Panel corresponds to controls. The recombinant WT protein is indicated as Gal-1 and the monomeric variant is indicated as M-Gal-1. Immunoreactivities of PlexinA4, Sema3A and NRP-1 antibodies were confirmed by immunoblotting on total lysates from spinal cord tissue

full neuroregenerative effect through binding to NRP-1 but also contributes to deactivating microglia ${ }^{20}$ and dampening pathogenic immune cells, ${ }^{55}$ the coordinated action of these biological effects may lead to a better restorative process after medullar lesion.

In summary, the results presented here provide the rational basis for the use of a stable dimeric form of Gal-1 as a potential agent for the treatment of human $\mathrm{SCl}$ patients.

\section{Methods}

Animal and surgical procedures. Male C57BL/6 WT and C57BL/6 Lgals $1^{-1-}$ mice (kindly provided by F Poirier, Jacques Monod Institut,
Paris, France) were used between 8 and 10 weeks of age (weight: 23-28g). Animal care and treatment were carried out according to guidelines of the experimental animal care committee of the School of Pharmacy and Biochemistry of the University of Buenos Aires, Buenos Aires, Argentina. Mice were anesthetized with ketamine ( $65 \mathrm{mg}$ per $\mathrm{kg}$ body weight) and xilacine ( $15 \mathrm{mg}$ per $\mathrm{kg}$ body weight) in a $600-\mu$ l solution to allow for an anesthetic effect and to prevent a possible dehydration process. Under a dissecting microscope (Leica EZ4, Wetzlar, Germany), mice received a complete spinal cord transection at the Th9-Th10 lamina level as previously described. ${ }^{52,56}$ Briefly, after Th9-Th10 laminectomy, the dura was opened and the spinal cord was transected using a surgical blade (Feather, Ribbel International Ltd., New Delhi, India). The severed ends of the cord were inspected to check for a complete transection. Surrounding muscles and skin were shut in layers. After the operation, mice were kept warm, placed in an incubator for $3 \mathrm{~h}$ and given manual bladder evacuation twice a day. Food was 
a
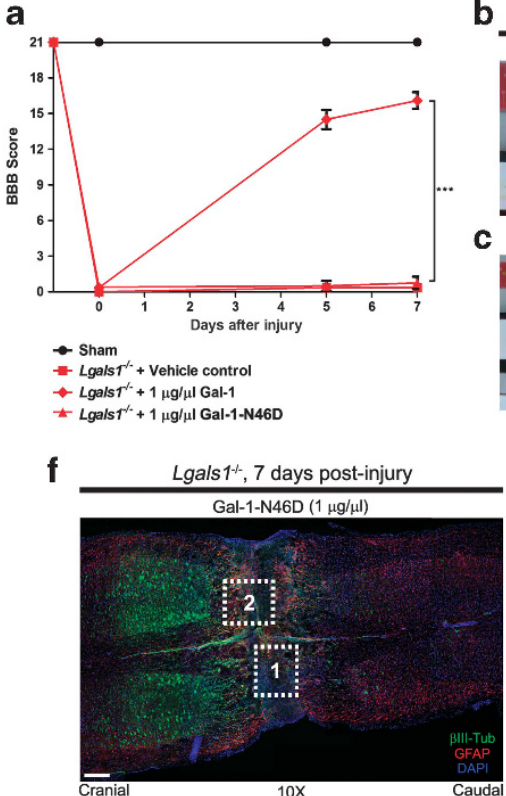

b

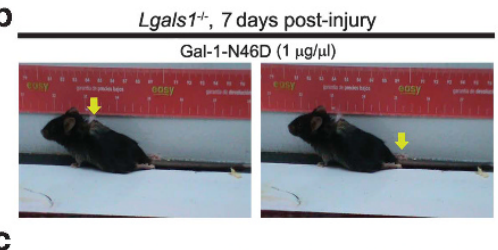

d

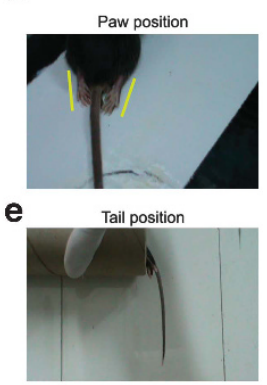

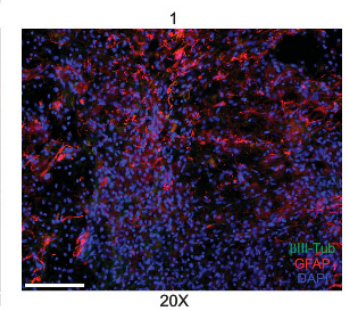

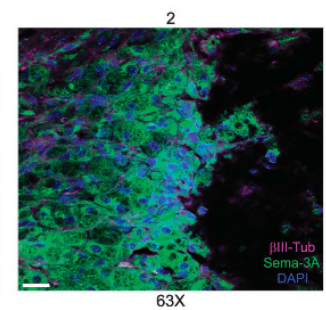

Figure 10 Assesment of hindlimb movements induced by treatment with $1 \mu \mathrm{g} / \mu \mathrm{l}$ Gal-1-N46D mutant. (a) BBB scoring. Values represent the mean \pm S.D. of four independent experiments ( $n=4$ mice per group). ${ }^{* * *} P<0.001$ using one-way ANOVA followed by Tukey's tests. (b) Representative video images. Yellow arrows show spinal column and tail positions. (c) Representative images of a mouse on a bridge-shaped metal grid. (d and e) The images indicate placement of paw (yellow lines) and tail position, respectively. (f) Triple staining with $\beta$ III-tubulin, GFAP and DAPI (4,6-diamidino-2-phenylindole). Scale bar, $250 \mu \mathrm{m}$. The right figures correspond to magnification of dotted frames 1 and 2. A representative triple staining with $\beta \| I$-tubulin, GFAP and DAPI (frame 1) and with $\beta I I$-tubulin, Sema3A and DAPI (frame 2) show injured neurons at the lesion site. Scale bars: $150 \mu \mathrm{m}$ for $\times 20 ; 20 \mu \mathrm{m}$ for $\times 63$

provided on the cage floor, and water bottles were placed within reach. For retransection studies, surgical processes were performed in the same manner 8 days after the first transection.

Administration of Gal-1 in injured spinal cord. At the time of transection, $10 \mu \mathrm{l}$ of a recombinant WT Gal-1 form occurring in a monomer-dimer equilibrium (Gal-1), a stable monomeric mutant (M-Gal-1) or a mutant lacking carbohydrate-binding activity (Gal-1-N46D) was applied at different concentrations $(0.5-1 \mu \mathrm{g} / \mu \mathrm{l})$ perpendicularly to the epicenter of the lesion site and in a $45^{\circ}$ angle in both cranial and caudal orientation. In control mice, the same volume of PBS was instilled. The injection was applied using microcapillary calibrated pipettes connected to a pump driven through a floor pedal. This process was performed under a dissecting microscope.

Quantification of astroglial processes and arborization. Quantification was developed using the Imaris 3D program 6.3.1 IMARIS 6.3.1 (Bitplane Sci Software, Zürich, Switzerland). Images were obtained using an Olympus Fluoview 1000 Confocal Microscope (Olympus Headquarters Corporate, Philadelphia, PA, USA), imported to this program in a calibrated format and then analyzed using the filament function. To develop this process, the confocal images were collected in high magnification $(\times 63$ objective, NA, 1.45; oil immersion) and taking $z$-series of 40-50 optical slices of airy unit $=1$ airy-disc at $0.2-\mu \mathrm{m}$ intervals in accordance with the Nyquist theory (optimum overlapping to minimize photobleaching). With the same settings, the confocal images were obtained to develop 3D reconstruction images to perform the 3D colocalization analysis as previously described. ${ }^{57}$

Assessment of the spinal cord scar and regenerated axons. Quantification of the spinal cord scar, lesion and neurite-regenerated areas were performed using the Fiij program (v.1.45) (NIH; Bethesda, MA, USA) with an area measurement and a calibration/set scale plug-in for the pre-calibration of each image. To determine the area occupied by motoneurons upstream/downstream of the lesion as well as neurite-regeneration area at the lesion site in gray and white matter, we used an area measurement plug-in with a threshold color plug-in to set the limits of both structures. Images were measured four times and averaged for each situation. This process was developed using epifluorescence microscopy
(Olympus BX51, with DP73 Cool Camera). Images were collected at different magnification levels $(\times 4, \times 10, \times 20$ objectives and NA, 0.13, 0.30, 0.50, respectively). Images were then deconvolved using Huygens compute engine 3.5.2p3 64b (closed platform) or a Parallel Spectral deconvolution plug-in from the Fiji program (open platform) with Tikhonov method and Laplacian stencil. For this case, the theoretical Point Spread Function (PSF) was obtained using a Diffraction PSF 3D plug-in from the Fiji program. For the case of quantification of regenerated axons, we collected confocal $z$-series images ( 30 optical slices of airy unit $=1$ airydisc at $0.25 \mu \mathrm{m}$ intervals using $\times 40$ objective) at the lesion site $(x / y)$ and performed a 3D projection following an automatic axon counter using a thresholdanalyze particle plug-in from the Fiji program.

CTB retrograde tracing and quantification. Retrograde tracing was performed as previously described ${ }^{58,59}$ with some modifications. Briefly, 8 days after $\mathrm{SCl}$, animals were injected with $2.5 \mu \mathrm{l}$ of CTB conjugated to Alexa fluor 488 dye (CTB; $10 \mathrm{mg} / \mathrm{ml}$; Molecular Probes Inc., Eugene, OR, USA) into the right and left gastrocnemius/sciatic nerve to trace motor circuitry in the spinal cord. Three days after the tracer injection, mice were killed by perfusionfixation and spinal cord lumbar segments were dissected in $45-\mu \mathrm{m}$ cryostat longitudinal (cranial to caudal) sections. The quantification of CTB-positive cell bodies was performed on three serial sections corresponding to ventral horn segments from each animal in triplicate. The total number of CTB-positive cell bodies in each sample was calculated as the addition of the count in each serial section. The counting was performed using the analyze particle plug-in from the Fiji program.

Behaviour experiments. To examine the effect of Gal-1 on neurological recovery, we used two behavioral tests on days 0,5 and 7 post transection and on days 1, 4 and 15 post retransection. The behavioral assessments were performed in a flat open field and in a grid-walking apparatus according to the abilities of each animal. Animals were acclimatized in an open field only for two 10-min cycles 4 days after $\mathrm{SCl}$ (1 day before starting the tests).

Open field locomotor test. Mice were evaluated in an open field platform $(1 \mathrm{~m}$ length); the recording was carried out in high definition from three different angles (lateral, above and behind). Animals were assigned a BBB score for hindlimb movement using the BBB motor rating scale. ${ }^{60}$ 
Grid-walking apparatus test. A curved bridge-shaped metal grid (each grid cell $5 \times 5 \mathrm{~cm}^{2}$ ) was used to test the animals' skilled walking. After each trial, $70 \%$ ethanol was used to clean the apparatus. The recording was carried out in high definition from above. The number of foot fall errors where the hindlimb failed to grasp a bar and falls between the bars was quantified (0-10 scale) per crossing. The animals were allowed to walk over the grid three times.

Behavioral tests were carried out in a sound-attenuated room. The analysis for both tests was developed later by two experimenters who were blind to the experimental design.

Statistical analysis. Graph-Pad Prism software Version 5.0 (Graph-Pad software, Inc., La Jolla, CA, USA) was used for data analysis. Results are presented as mean \pm S.D. Comparisons were performed using unpaired onetailed Student's t-test or one-way analysis of variance (ANOVA) followed by Tukey's post hoc tests, where appropriate.

\section{Conflict of Interest}

The authors declare no conflict of interest.

Acknowledgements. We thank to Dr. F Poirier for Lgals $1^{-/-}$mice, J Wang for N46D mutant, L Baum for M-Gal-1 mutant, P Lopez for HB9 and R Rosenstein for CTB Alexa 488. We are grateful to S Di Lella and D Croci for assistance in the purification of Gal-1 protein and mutants; MP Roberti for critically reading the manuscript and $\mathrm{J}$ Correale for helpful insights. This study was supported by grants from the Argentinean Agency for Promotion of Science and Technology (PICT 2008-1182), Argentinean National Council of Scientific and Technical Investigation and University of Buenos Aires (UBACYT 2011-14, no. 20020100100393) to LAP, Agency for Promotion of Science and Technology (PICT 2008-0791) to JMP and grants from NMSS (RG4530), the Argentinean Agency for Promotion of Science and Technology (PICT 2010-870) and Fundación Sales to GAR.

\section{Author contributions}

$H R Q$ performed all the experiments, $H R Q$ and LAP designed the experiments and JMP and LAP supported, coordinated and supervised the project. GAR supervised biochemical experiments. All the authors wrote the manuscript.

1. Yezierski RP. Spinal cord injury pain: spinal and supraspinal mechanisms. J Rehabil Res Dev 2009; 46: 95-107.

2. Pasterkamp RJ, Anderson PN, Verhaagen J. Peripheral nerve injury fails to induce growth of lesioned ascending dorsal column axons into spinal cord scar tissue expressing the axon repellent Semaphorin3A. Eur J Neurosci 2001; 13: 457-471.

3. Pasterkamp RJ, Giger RJ, Ruitenberg MJ, Holtmaat AJ, De Wit J, De Winter F et al. Expression of the gene encoding the chemorepellent semaphorin III is induced in the fibroblast component of neural scar tissue formed following injuries of adult but not neonatal CNS. Mol Cell Neurosci 1999; 13: 143-166.

4. De Winter F, Oudega M, Lankhorst AJ, Hamers FP, Blits B, Ruitenberg MJ et al. Injury-induced class 3 semaphorin expression in the rat spinal cord. Exp Neurol 2002; 175 : 61-75.

5. Kolodkin AL, Matthes DJ, Goodman CS. The semaphorin genes encode a family of transmembrane and secreted growth cone guidance molecules. Cell 1993; 75: 1389-1399.

6. Kolodkin AL, Levengood DV, Rowe EG, Tai YT, Giger RJ, Ginty DD. Neuropilin is a semaphorin III receptor. Cell 1997; 90: 753-762.

7. He Z, Tessier-Lavigne M. Neuropilin is a receptor for the axonal chemorepellent Semaphorin III. Cell 1997; 90: 739-751.

8. Pasterkamp RJ, Kolodkin AL. Semaphorin junction: making tracks toward neural connectivity. Curr Opin Neurobiol 2003; 13: 79-89.

9. Tamagnone L, Artigiani S, Chen H, He Z, Ming Gl, Song $\mathrm{H}$ et al. Plexins are a large family of receptors for transmembrane, secreted, and GPI-anchored semaphorins in vertebrates. Cell 1999; 99: 71-80.

10. De Winter F, Holtmaat AJ, Verhaagen J. Neuropilin and class 3 semaphorins in nervous system regeneration. Adv Exp Med Biol 2002; 515: 115-139.

11. Lindholm T, Sköld MK, Suneson A, Carlstedt T, Cullheim S, Risling M. Semaphorin and neuropilin expression in motoneurons after intraspinal motoneuron axotomy. Neuroreport 2004; 15: 649-654

12. Pasterkamp RJ, Verhaagen J. Emerging roles for semaphorins in neural regeneration. Brain Res Brain Res Rev 2001; 35: 36-54.

13. Rabinovich GA, Croci DO. Regulatory circuits mediated by lectin-glycan interactions in autoimmunity and cancer. Immunity 2012; 36: 322-335.

14. Sakaguchi M, Shingo T, Shimazaki T, Okano HJ, Shiwa M, Ishibashi $S$ et al. A carbohydrate-binding protein, Galectin-1, promotes proliferation of adult neural stem cells. Proc Natl Acad Sci USA 2006; 103: 7112-7117.
15. Kaijtani K, Nomaru H, Ifuku M, Yutsudo N, Dan Y, Miura T et al. Galectin-1 promotes basal and kainate-induced proliferation of neural progenitors in the dentate gyrus of adult mouse hippocampus. Cell Death Differ 2009; 16: 417-427.

16. Ishibashi S, Kuroiwa T, Sakaguchi M, Sun L, Kadoya T, Okano H et al. Galectin-1 regulates neurogenesis in the subventricular zone and promotes functional recovery after stroke. Exp Neurol 2007; 207: 302-313.

17. Yamane J, Nakamura M, Iwanami A, Sakaguchi M, Katoh $H$, Yamada $M$ et al. Transplantation of galectin-1-expressing human neural stem cells into the injured spinal cord of adult common marmosets. J Neurosci Res 2010; 88: 1394-1405.

18. Han H, Xia Y, Wang S, Zhao B, Sun Z, Yuan L. Synergistic effects of galectin-1 and reactive astrocytes on functional recovery after contusive spinal cord injury. Arch Orthop Trauma Surg 2011; 131: 829-839.

19. McGraw J, Oschipok LW, Liu J, Hiebert GW, Mak CF, Horie H et al. Galectin-1 expression correlates with the regenerative potential of rubrospinal and spinal motoneurons. Neuroscience 2004; 128: 713-719.

20. Starossom SC, Mascanfroni ID, Imitola J, Cao L, Raddassi K, Hernandez SF et al. Galectin-1 deactivates classically activated microglia and protects from inflammationinduced neurodegeneration. Immunity 2012; 37: 249-263.

21. Metz GA, Merkler D, Dietz V, Schwab ME, Fouad K. Efficient testing of motor function in spinal cord injured rats. Brain Res 2000; 883: 165-177.

22. Soblosky JS, Colgin LL, Chorney-Lane D, Davidson JF, Carey ME. Ladder beam and camera video recording system for evaluating forelimb and hindlimb deficits after sensorimotor cortex injury in rats. J Neurosci Methods 1997; 78: 75-83.

23. Popovich PG, Guan Z, Wei P, Huitinga I, van Rooijen N, Stokes BT. Depletion of hematogenous macrophages promotes partial hindlimb recovery and neuroanatomical repair after experimental spinal cord injury. Exp Neurol 1999; 158: 351-365.

24. Jones TB, McDaniel EE, Popovich PG. Inflammatory-mediated injury and repair in the traumatically injured spinal cord. Curr Pharm Des 2005; 11: 1223-1236.

25. Loane DJ, Byrnes KR. Role of microglia in neurotrauma. Neurotherapeutics 2010; 7 366-377.

26. Tian DS, Yu ZY, Xie MJ, Bu BT, Witte OW, Wang W. Suppression of astroglial scar formation and enhanced axonal regeneration associated with functional recovery in a spinal cord injury rat model by the cell cycle inhibitor olomoucine. J Neurosci Res 2006; 84: 1053-1063.

27. Tian DS, Xie MJ, Yu ZY, Zhang Q, Wang YH, Chen B et al. Cell cycle inhibition attenuates microglia induced inflammatory response and alleviates neuronal cell death after spinal cord injury in rats. Brain Res 2007; 1135: 177-185.

28. Lin RC, Matesic DF, Marvin M, McKay RD, Brustle O. Re-expression of the intermediate filament nestin in reactive astrocytes. Neurobiol Dis 1995; 2 : 79-85.

29. Raineteau O, Schwab ME. Plasticity of motor systems after incomplete spinal cord injury. Nat Rev Neurosci 2001; 2: 263-273.

30. Cafferty WB, McGee AW, Strittmatter SM. Axonal growth therapeutics: regeneration or sprouting or plasticity? Trends Neurosci 2008; 31: 215-220.

31. Conde C, Caceres A. Microtubule assembly, organization and dynamics in axons and dendrites. Nat Rev Neurosci 2009; 10: 319-332.

32. Quinta HR, Galigniana MD. The neuroregenerative mechanism mediated by the Hsp90-binding immunophilin FKBP52 resembles the early steps of neuronal differentiation. Br J Pharmacol 2012; 166: 637-649.

33. Calderon de Anda F, Gartner A, Tsai LH, Dotti CG. Pyramidal neuron polarity axis is defined at the bipolar stage. J Cell Sci 2008; 121: 178-185.

34. Gomis-Ruth S, Wierenga CJ, Bradke F. Plasticity of polarization: changing dendrites into axons in neurons integrated in neuronal circuits. Curr Biol 2008; 18: 992-1000.

35. Barrionuevo $\mathrm{P}$, Beigier-Bompadre M, Ilarregui JM, Toscano MA, Bianco GA, Isturiz MA et al. A novel function for galectin-1 at the crossroad of innate and adaptive immunity: galectin-1 regulates monocyte/macrophage physiology through a nonapoptotic ERKdependent pathway. J Immunol 2007; 178: 436-445.

36. Kaneko S, Iwanami A, Nakamura M, Kishino A, Kikuchi K, Shibata S et al. A selective Sema3A inhibitor enhances regenerative responses and functional recovery of the injured spinal cord. Nat Med 2006; 12: 1380-1389.

37. Bareyre FM, Kerschensteiner M, Raineteau O, Mettenleiter TC, Weinmann O, Schwab ME. The injured spinal cord spontaneously forms a new intraspinal circuit in adult rats Nat Neurosci 2004; 7: 269-277.

38. Outenreath RL, Jones AL. Influence of an endogenous lectin substrate on cultured dorsal root ganglion cells. J Neurocytol 1992; 21: 788-795.

39. McGraw J, McPhail LT, Oschipok LW, Horie H, Poirier F, Steeves JD et al. Galectin-1 in regenerating motoneurons. Eur J Neurosci 2004; 20: 2872-2880.

40. Rabinovich GA, Rubinstein N, Fainboim L. Unlocking the secrets of galectins: a challenge at the frontier of glyco-immunology. J Leukoc Biol 2002; 71: 741-752.

41. McGraw J, Gaudet AD, Oschipok LW, Kadoya T, Horie H, Steeves JD et al. Regulation of neuronal and glial galectin-1 expression by peripheral and central axotomy of rat primary afferent neurons. Exp Neurol 2005; 195: 103-114.

42. Horie $\mathrm{H}$, Inagaki $\mathrm{Y}$, Sohma $\mathrm{Y}$, Nozawa R, Okawa K, Hasegawa M et al. Galectin-1 regulates initial axonal growth in peripheral nerves after axotomy. J Neurosci 1999; 19: 9964-9974.

43. Fukaya K, Hasegawa M, Mashitani T, Kadoya T, Horie H, Hayashi $\mathrm{Y}$ et al. Oxidized galectin-1 stimulates the migration of Schwann cells from both proximal and distal stumps 
of transected nerves and promotes axonal regeneration after peripheral nerve injury. J Neuropathol Exp Neurol 2003; 62: 162-172.

44. Cho M, Cummings RD. Characterization of monomeric forms of galectin-1 generated by site-directed mutagenesis. Biochemistry 1996; 35: 13081-13088.

45. Hsieh SH, Ying NW, Wu MH, Chiang WF, Hsu CL, Wong TY et al. Galectin-1, a novel ligand of neuropilin-1, activates VEGFR-2 signaling and modulates the migration of vascular endothelial cells. Oncogene 2008; 27: 3746-3753.

46. Kim JE, Li S, GrandPre T, Qiu D, Strittmatter SM. Axon regeneration in young adult mice lacking Nogo-A/B. Neuron 2003; 38: 187-199.

47. Zheng B, Ho C, Li S, Keirstead H, Steward O, Tessier-Lavigne M. Lack of enhanced spinal regeneration in Nogo-deficient mice. Neuron 2003; 38: 213-224.

48. Zheng B, Atwal J, Ho C, Case L, He XL, Garcia KC et al. Genetic deletion of the Nogo receptor does not reduce neurite inhibition in vitro or promote corticospinal tract regeneration in vivo. Proc Natl Acad Sci USA 2005; 102: 1205-1210.

49. Bradbury EJ, Moon LD, Popat RJ, King VR, Bennett GS, Patel PN et al. Chondroitinase $A B C$ promotes functional recovery after spinal cord injury. Nature 2002; 416: 636-640.

50. Cai D, Shen Y, De Bellard M, Tang S, Filbin MT. Prior exposure to neurotrophins blocks inhibition of axonal regeneration by MAG and myelin via a cAMP-dependent mechanism. Neuron 1999; 22: 89-101.

51. Li S, Liu BP, Budel S, Li M, Ji B, Walus L et al. Blockade of Nogo-66, myelin-associated glycoprotein, and oligodendrocyte myelin glycoprotein by soluble Nogo-66 recepto promotes axonal sprouting and recovery after spinal injury. $J$ Neurosci 2004; 24 : 10511-10520.
52. Bregman BS. Spinal cord transplants permit the growth of serotonergic axons across the site of neonatal spinal cord transection. Brain Res 1987; 431: 265-279.

53. Kikuchi K, Kishino A, Konishi O, Kumagai K, Hosotani N, Saji I et al. In vitro and in vivo characterization of a novel semaphorin 3A inhibitor, SM-216289 or xanthofulvin. J Biol Chem 2003; 278: 42985-42991.

54. Kumagai K, Hosotani N, Kikuchi K, Kimura T, Saji I. Xanthofulvin, a novel semaphorin inhibitor produced by a strain of Penicillium. J Antibiot (Tokyo) 2003; 56: 610-616.

55. Kadoya T, Horie H. Structural and functional studies of galectin-1: a novel axonal regeneration-promoting activity for oxidized galectin-1. Curr Drug Targets 2005; 6: 375-383.

56. Bregman BS. Development of serotonin immunoreactivity in the rat spinal cord and its plasticity after neonatal spinal cord lesions. Brain Res 1987; 431: 245-263.

57. Quinta HR, Maschi D, Gomez-Sanchez C, Piwien-Pilipuk G, Galigniana MD. Subcellular rearrangement of hsp90-binding immunophilins accompanies neuronal differentiation and neurite outgrowth. J Neurochem 2010; 115: 716-734.

58. Xu L, Ryugo DK, Pongstaporn T, Johe K, Koliatsos VE. Human neural stem cell grafts in the spinal cord of SOD1 transgenic rats: differentiation and structural integration into the segmental motor circuitry. J Comp Neurol 2009; 514: 297-309.

59. Hirakawa M, McCabe JT, Kawata M. Time-related changes in the labeling pattern of motor and sensory neurons innervating the gastrocnemius muscle, as revealed by the retrograde transport of the cholera toxin B subunit. Cell Tissue Res 1992; 267: 419-427.

60. Basso DM, Beattie MS, Bresnahan JC. Graded histological and locomotor outcomes after spinal cord contusion using the NYU weight-drop device versus transection. Exp Neurol 1996; 139: 244-256.

Supplementary Information accompanies this paper on Cell Death and Differentiation website (http://www.nature.com/cdd) 